\title{
Effect of Tungsten Alloying on Short-to-Medium-Range-Order Evolution and Crystallization Behavior of Near-Eutectic Amorphous Ni-P
}

\author{
Xun Zhan, ${ }^{1}$ Pei Zhang, ${ }^{2}$ Paul M. Voyles, ${ }^{2}$ Xinyu Liu, ${ }^{3}$ Rohan Akolkar ${ }^{3}$, Frank Ernst ${ }^{1 *}$ \\ ${ }^{1}$ Department of Materials Science and Engineering, Case Western Reserve University, \\ Cleveland, OH 44106-7204, USA. \\ ${ }^{2}$ Department of Materials Science and Engineering, University of Wisconsin, \\ Madison, Madison, WI 53706, USA. \\ ${ }^{3}$ Department of Chemical and Biomolecular Engineering, Case Western Reserve University, \\ Cleveland, OH 44106-7217, USA.
}

\begin{abstract}
The crystallization of near-eutectic amorphous Ni-P can be significantly retarded by alloying a small fraction of tungsten. To understand this phenomenon, amorphous $\mathrm{Ni}_{0.80} \mathrm{P}_{0.20}$ and $\mathrm{Ni}_{0.76} \mathrm{~W}_{0.04} \mathrm{P}_{0.20}$ with the same phorphous fraction were fabricated by electroless plating as $10 \mu \mathrm{m}$-thick continuous layers. Subsequently, the alloys were tempered to three different stages: (i) an "incubation stage" (still completely amorphous), (ii) a "partially crystalline" stage (amorphous and crystalline phases), and (iii) a "completely crystalline" stage (only crystalline phases). To understand the strong effect of tungsten alloying on the crystallization behavior, we investigate the atomistic structure of as-plated and tempered $\mathrm{Ni}_{0.76} \mathrm{~W}_{0.04} \mathrm{P}_{0.20}$ and compare it with that of correspondingly treated amorphous $\mathrm{Ni}_{0.80} \mathrm{P}_{0.20}$. The study focuses on SRO (short-range order) and MRO (medium-range order). SRO, characterized by typical nearest neighbors, was studied by XPS (X-ray photoelectron spectrometry). MRO, which includes neighbor atoms up to about $2 \mathrm{~nm}$ distance, was studied by FEM (fluctuation electron microscopy). In addition, the crystalline phases and microstructure of both alloys were studied by XRD (X-ray diffractometry) and TEM (transmission electron microscopy), respectively.
\end{abstract}

\footnotetext{
${ }^{*}$ Corresponding author

Email address: frank.ernst@case.edu
} 
Combining results of these complimentary techniques leads to models for the atomistic structure of amorphous $\mathrm{Ni}-\mathrm{P}$ and $\mathrm{Ni}-\mathrm{W}-\mathrm{P}$ and models for the micromechanism of crystallization. Specifically, these models explain why tungsten reduces the driving force for crystallization and slows the crystallization kinetics. The principles we have recognized may be useful for identifying alloying elements that are potentially even more effective in retarding crystallization.

Keywords: Amorphous $\mathrm{Ni}_{0.80} \mathrm{P}_{0.20}$ and $\mathrm{Ni}_{0.76} \mathrm{~W}_{0.04} \mathrm{P}_{0.20}$, atomistic structure, fluctuation electron microscopy, crystallization microstructure

\section{Introduction}

Amorphous $\mathrm{Ni}-\mathrm{P}$ alloys fabricated by electroless plating are widely used as buffer layers for rigidmemory disc platters. Critical material properties include uniformity, isotropy of properties, ease of polishing, and paramagnetic characteristics $[1,2]$. However, the poor thermal stability of $\mathrm{Ni}-\mathrm{P}$ is limiting for further industrial process development. Many researchers have found that by adding a third element, such as tungsten, Mo, or Re [3, 4], crystallization of amorphous $\mathrm{Ni}-\mathrm{P}$ can be significantly retarded, i. e. requiring higher temperature for the same transformation rate or requiring longer times for the same transformed fraction. Until now, the micro-mechanism of retardation is still not clear; the screening of the periodic table for an efficient third element is generally "blind." In order to identify the most effective alloying element, i. e. obtaining the highest crystallization temperature with the smallest amount of alloying element, it is necessary to understand the physical background. This includes understanding the impact of the alloying element on the atomistic structure of as-plated amorphous $\mathrm{Ni}-\mathrm{P}$ and its impact on the micro-mechanism of crystallization.

The atomistic structure of prototypical amorphous Ni-P alloys has been extensively studied since the 1970s, including their SRO (short-range order) (typically the nearest neighbor) and MRO (medium-range order) (typically beyond the nearest neighbor and extending to $\approx 2 \mathrm{~nm}$ distance). Specifically, Cargill [5] compared the measured PDF (pair distribution function) with the results of calculations based on Bernal's DRPHS (dense random packing of hard spheres) model [6] and obtained good agreement between experiment and simulation. In the Bernal model, both $\mathrm{Ni}$ and phosporous atoms are considered as hard spheres of the same size, based on their similar Goldschmidt radii. However, this approach predicts a density that is smaller than that obtained by 
experimental measurement. Polk [7] proposed that the Ni atoms follow a DRPHS configuration, while the phosporous atoms reside in canonical holes. Unfortunately, this DRPHS model shows obvious inconsistencies of expected and experimentally observed intensity of PDF sub-peaks. The major problem of DRPHS models is that they ignore the relatively strong order in amorphous $\mathrm{Ni}_{0.80} \mathrm{P}_{0.20}$, which has been confirmed by various kinds of experimental observations $[8,9]$. Rather, those observations support the stereochemical model proposed by Gaskell [10]. That model suggests that the SRO in amorphous alloys is well developed and almost identical to that in the corresponding crystals. The model implies that the main difference between amorphous and crystalline structure lies in the MRO, i. e., ordered versus random packing of stereochemical units. Gaskell proposed that the stereochemical unit for Ni-P is a TTP (tri-capped trigonal prism) with nine Ni atoms at the shell and one phosphorus atom in the center, as found in crystalline $\mathrm{Ni}_{3} \mathrm{P}$ (graphically shown in Fig 9, discussed later). Moreover, Gaskell suggested a chain-like connection of the TTP units by sharing edges.

Although the stereochemical model successfully reproduces the experimentally observed PDF, the unique stereochemical unit theory was overturned by later studies. Lamparter et al. [11] simulated PPDFs (partial pair distribution functions) of Ni-P by a RMC (reverse monte carlo) and found that distorted TTP can also fit the experimental PPDFs almost perfectly. Most recently, Sheng et al. [12] proposed a model of efficient packing of quasi-equivalent phosphorus-centered clusters by fitting experimental data of synchrotron XRD (X-ray diffractometry) and EXAFS (extended X-ray absorption fine structure) with the RMC and ab initio MD (molecular dynamics) simulations. That model confirms strong chemical order in amorphous $\mathrm{Ni}_{0.80} \mathrm{P}_{0.20}$ : the $\mathrm{SRO}$ is dominated by $\mathrm{Ni}-\mathrm{P}$ clusters, while $\mathrm{P}-\mathrm{P}$ bonds are avoided. Moreover, the SRO is not necessarily the same as in crystalline $\mathrm{Ni}_{0.80} \mathrm{P}_{0.20}$, but determined by the effective size ratio of $\mathrm{Ni}$ and phosphorus as well as the chemical composition. The SRO of amorphous $\mathrm{Ni}-\mathrm{P}$ allows for intrinsic distortions and quasi-equivalent clusters. The MRO was proposed to correspond to dense random packing of these clusters, which usually have shapes approximating five-fold icosaheders and share outer Ni atoms.

The previously described experimental methods reveal mostly SRO information of amorphous alloys, but lack sensitivity for structural information of MRO. Therefore, the simulations based on such experimental data as well as corresponding structure models mainly concern the SRO of amorphous Ni-P alloys. Recently, FEM (fluctuation electron microscopy), a TEM (transmission 
electron microscopy) technique to study MRO in amorphous materials [13, 14], has been broadly applied to amorphous semiconductors [15], amorphous oxides [16], and metallic glasses [17-19]. FEM can be performed by obtaining nanodiffraction patterns in STEM (scanning transmission electron microscopy) mode [20]. With the electron beam rastering over the specimen, the local electron diffractogram intensity $I[\boldsymbol{k}, \boldsymbol{r}]$ is recorded as a function of diffraction (scattering) vector $\boldsymbol{k}$ and location $\boldsymbol{r}$. Adjustable parameters include the beam diameter, impacting the spatial resolution $R$ and the specimen thickness $h$, assumed to be constant over the field of view. The MRO and information on structure-heterogeneity can be obtained by calculating the normalized intensity variance

$$
V[\boldsymbol{k}, R]=\frac{\left\langle I[\boldsymbol{k}, R, \boldsymbol{r}]^{2}\right\rangle_{r}}{\langle I[\boldsymbol{k}, R, \boldsymbol{r}]\rangle_{r}^{2}}-1
$$

where $\langle\ldots\rangle_{r}$ means the average over all sampling positions $\boldsymbol{r}$. Generally, if the sampling area is a single crystal, $V[\boldsymbol{k}, R]=0 \forall \boldsymbol{k}$. If the specimen structure is strongly ordered on a length scale of $R$, $V[\boldsymbol{k}, R]$ will show strong peaks at diffraction vectors $\boldsymbol{k}$ that fulfill Bragg conditions. On the other hand, $V[\boldsymbol{k}, R]=0 \forall \boldsymbol{k}$ is also expected if the sampling area is completely random.

Wen et al. [21] simulated $V[\boldsymbol{k}]$ of Ni-P based on an MKA (modified Kob-Anderson) model [21] and an ECP (efficient cluster packing) model [22]. For both approaches, the simulated $V[\boldsymbol{k}]$ shows a well-developed peak at $4.8 \mathrm{~nm}^{-1}$ and a weak peak at $8.3 \mathrm{~nm}^{-1}$. Both peaks are absent from the $V[\boldsymbol{k}]$ of liquid $\mathrm{Ni}_{0.80} \mathrm{P}_{0.20}$. However, corresponding experimental FEM data of amorphous $\mathrm{Ni}-\mathrm{P}$ are not available for comparison.

Compared to amorphous $\mathrm{Ni}_{0.80} \mathrm{P}_{0.20}$, not much information is available on the atomistic structure of ternary amorphous alloys of the type $\mathrm{Ni}-\mathrm{Me}-\mathrm{P}$, where Me represents a metal. One well-studied example is $\mathrm{Pd}_{x} \mathrm{Ni}_{0.80-x} \mathrm{P}_{0.20}$, where $0.20 \leq x \leq 0.70$ [23, 24]. Specifically, Alamgir et al. [23] studied the effect of alloying on the chemical bonding and GFA (glass-forming ability) of $\mathrm{Pd}_{x} \mathrm{Ni}_{0.80-x} \mathrm{P}_{0.20}$ by analyzing core-level binding energies of $\mathrm{Pd}, \mathrm{Ni}$, and phosphorus using XPS (X-ray photoelectron spectrometry). They found that the atoms in the glassy and corresponding crystalline alloys generally have similar chemical environments, especially for the composition $x=0.40$, which is known as the best glass former in the $\mathrm{Pd}-\mathrm{Ni}-\mathrm{P}$ system [25]. Further, Alamgir et al. [24] investigated the SRO around all three constituent atoms in amorphous $\mathrm{Pd}_{x} \mathrm{Ni}_{0.80-x} \mathrm{P}_{0.20}$ by EXELFS (extended energy-loss fine structure) and EXAFS. They found that the environment of Pd in Pd-rich glass can be well described as that of $\mathrm{Pd}$ in crystalline $\mathrm{Pd}_{3} \mathrm{P}$. Similarly, the environment of $\mathrm{Ni}$ in amorphous 
Ni-rich $\mathrm{Pd}_{x} \mathrm{Ni}_{0.80-x} \mathrm{P}_{0.20}$ is isostructural with that of $\mathrm{Ni}$ in crystalline $\mathrm{Ni}_{3} \mathrm{P}$. The crystal structures of $\mathrm{Pd}_{3} \mathrm{P}$ and $\mathrm{Ni}_{3} \mathrm{P}$ both have TTP structural units. For the best glass former, $\mathrm{Pd}_{40} \mathrm{Ni}_{40} \mathrm{P}_{20}$, the environment of the metal atoms is a weighted average of the environments of $\mathrm{Pd}$ in $\mathrm{Pd}_{3} \mathrm{P}$ and $\mathrm{Ni}$ in $\mathrm{Ni}_{3} \mathrm{P}$. The combination of the two SROs provides $\mathrm{Pd}_{40} \mathrm{Ni}_{40} \mathrm{P}_{20}$ with good GFA.

Inoue [26] and Hosokawa [27] studied quaternary amorphous systems, particularly amorphous $\mathrm{Pd}-$ $\mathrm{Ni}-\mathrm{Cu}-\mathrm{P}$. That system has even better GFA than $\mathrm{Pd}-\mathrm{Ni}-\mathrm{P}$. To explain this, the authors suggested a MRO characterized by coexistence of TTP and a structure unit corresponding to a tetragonal dodecahedron, introduced by alloying $\mathrm{Cu}$.

To advance physical understanding of alloying effects on crystallization behavior, we here report a study of $\mathrm{Ni}-\mathrm{P}$ and $\mathrm{Ni}-\mathrm{W}-\mathrm{P}$ alloys with the same phosphorus fraction as prototypical materials. Both alloys were fabricated in the amorphous state by electroless plating. The SRO and MRO of as-plated as well as isothermally tempered $\mathrm{Ni}-\mathrm{P}$ and $\mathrm{Ni}-\mathrm{W}-\mathrm{P}$ were investigated by XPS and FEM, respectively. The influence of tungsten alloying on the SRO, MRO, and their evolution during tempering is revealed by comparing these data and using the developed atomistic structure models. Moreover, the influence of tungsten alloying on the microstructure of crystalline $\mathrm{Ni}-\mathrm{P}$ was analyzed by TEM. By a combined study of the short-to-medium range order evolution and the crystallization behavior, we uncover the role of tungsten in retarding crystallization of amorphous $\mathrm{Ni}_{0.80} \mathrm{P}_{0.20}$. The results provide general insights that are useful for identifying further alloying elements that are effective in retarding crystallization.

\section{Experimental Methods and Procedures}

The as-plated (as-received) materials, denoted as "AR" for Ni-P and "AR-W" for Ni-W-P (Table 1), were $10 \mu \mathrm{m}$ thick layers, plated onto $\mathrm{Al}$ substrates using electroless plating technique. Due to bath instability during $\mathrm{Ni}-\mathrm{W}-\mathrm{P}$ plating, the bath $\mathrm{pH}$ was finely controlled by adding $\mathrm{NaOH}$ or $\mathrm{H}_{2} \mathrm{SO}_{4}$ solution manually after short time intervals. The plating parameters of $\mathrm{Ni}-\mathrm{W}-\mathrm{P}$ are compiled in Table 2; further details will be published elsewhere [28]. After dissolving the Al substrates in a

$10 \% \mathrm{NaOH}$ solution at $313 \mathrm{~K}$, we punched out $\varnothing 3 \mathrm{~mm}$ discs for further study. The compositions were quantified by SEM (scanning electron microscopy)-based XEDS (X-ray energy-dispersive spectrometry). The measured compositions of the $\mathrm{Ni}-\mathrm{P}$ and $\mathrm{Ni}-\mathrm{W}-\mathrm{P}$ layers are listed in Table 3. 
The phosphorus fractions of the $\mathrm{Ni}-\mathrm{P}$ and $\mathrm{Ni}-\mathrm{W}-\mathrm{P}$ were $(19.8 \pm 0.1)$ at $\%$ and $(19.9 \pm 0.5)$ at $\%$, i. e. practically identical. The Ni-W-P constitutes a solid solution in which tungsten atoms substitute for $\mathrm{Ni}$ atoms. On the length scale accessible to SEM-based XEDS $(\approx 1 \mu \mathrm{m})$, the tungsten is uniformly distributed. Based on the compositions displayed in Table 3, we designate the composition of the $\mathrm{Ni}-\mathrm{P}$ and the $\mathrm{Ni}-\mathrm{W}-\mathrm{P}$ as $\mathrm{Ni}_{0.80} \mathrm{P}_{0.20}$ and $\mathrm{Ni}_{0.76} \mathrm{~W}_{0.04} \mathrm{P}_{0.20}$, respectively.

Isochronal $(0.33 \mathrm{~K} / \mathrm{s})$ DSC (differential scanning calorimetry), used for comparing the crystallization temperature of amorphous $\mathrm{Ni}_{0.80} \mathrm{P}_{0.20}$ and $\mathrm{Ni}_{0.76} \mathrm{~W}_{0.04} \mathrm{P}_{0.20}$, and isothermal crystallization, used for studying SRO, MRO, and microstructure evolution of these alloys, were operated using a Netzsch Pegasus 404 F1 DSC system under pure Ar at a flow rate of $0.3 \mathrm{ml} / \mathrm{s}$. Al pans with lids were used as sample holders. Temperature and enthalpy were calibrated by measuring the melting points and the heat of fusion of In-, Sn-, Bi-, and Zn standard specimens. For isothermal tempering, AR and AR-W were heated to $598 \mathrm{~K}$ and $650 \mathrm{~K}$, respectively, at a rate of $0.7 \mathrm{~K} / \mathrm{s}$, and then held for three different periods of time: $0.9 \mathrm{ks}, 1.5 \mathrm{ks}$, and $2.4 \mathrm{ks}$ (Table 1 ).

XRD was performed on as-plated and tempered $\mathrm{Ni}_{0.80} \mathrm{P}_{0.20}$ and $\mathrm{Ni}_{0.76} \mathrm{~W}_{0.04} \mathrm{P}_{0.20}$ using a Bruker Discover D8 X-ray diffractometer, equipped with a Co- $\mathrm{K}_{\alpha}$ monochromatic source $(\lambda=0.17889 \mathrm{~nm})$. The peak positions were calibrated with the help of an $\mathrm{Al}_{2} \mathrm{O}_{3}$ reference sample. Accordingly, AR, AR-W, T09, and T09-W are all amorphous, T15 and T15-W are partially crystalline, and T24, T24-W are completely crystalline (Table 1 ).

XPS was performed on AR, T09, T24 for $\mathrm{Ni}_{0.80} \mathrm{P}_{0.20}$ [29] and on $\mathrm{AR}-\mathrm{W}, \mathrm{T} 09-\mathrm{W}, \mathrm{T} 24-\mathrm{W}$ for $\mathrm{Ni}_{0.76} \mathrm{~W}_{0.04} \mathrm{P}_{0.20}$ (Table 1) at room temperature using a VersaProbe (Physical Electronics, Inc., USA), equipped with an Al- $\mathrm{K}_{\alpha}$ source $(h \nu=1486.6 \mathrm{eV})$. To remove the oxide layer before spectrum acquisition, the samples were cleaned in situ by Ar sputtering under conditions corresponding to high vacuum. The peak FWHM (full-width at half maximum) resolution was set to $0.7 \mathrm{eV}$, while the energy resolution for collecting the core-level photoelectrons was $0.2 \mathrm{eV}$. For energy calibration, we used the C-1s peak located at $(284.6 \pm 0.1) \mathrm{eV}$. The core-level binding energies of Ni-2p 3/2, $\mathrm{P}-2 \mathrm{p} 3 / 2$, and $\mathrm{W}-4 \mathrm{f} 7 / 2$ were determined by fitting the peaks using Multipak software.

TEM specimens were prepared from as-plated and partially crystallized $\mathrm{Ni}_{0.80} \mathrm{P}_{0.20}$ and $\mathrm{Ni}_{0.76} \mathrm{~W}_{0.04} \mathrm{P}_{0.20}$ alloys. Final thinning to electron transparency was accomplished with a Tenupol 5 (Struers Inc.), using an electrolyte of $10 \% \mathrm{HClO}_{4}$ (perchloric acid) and $90 \% \mathrm{CH}_{3}-\mathrm{OH}$ (methanol) at $\approx 230 \mathrm{~K}$. 
Before FEM measurements, TEM specimens were plasma-cleaned with a $0.15 \mathrm{kPa} \mathrm{Ar}+\mathrm{O}_{2}$ mixture for about $180 \mathrm{~s}$.

FEM experiments were performed on a $200 \mathrm{kV}$ Titan (FEI) equipped for STEM, including a spherical-aberration corrector for the probe-forming lens. The Schottky field-emission gun was operated at an extraction voltage of $4.5 \mathrm{kV}$. The instrument was operated in the "microprobe mode" with a probe diameter of $2 \mathrm{~nm}$ and a camera length of $512 \mathrm{~mm}$ in EFSTEM (energy-filtered STEM) mode with a $10 \mathrm{eV}$-wide slit. A Gatan annular dark-field detector, mounted on the $2.5 \mathrm{~mm}$ GIF (Gatan Imaging Filter) entrance aperture was used to collect STEM images simultaneously with the nanodiffraction patterns. The diffraction-lens current was adjusted using the FEI free-lens control interface to ensure good diffraction focus. $512 \times 512$-pixel ${ }^{2}$ nanodiffraction patterns were acquired with a CCD (charge-coupled device) camera binning of 4 on a $10 \times 10$ grid of positions covering a $30 \times 30 \mathrm{~nm}^{2}$ area of the sample. Variance data from ten different areas of each sample were averaged together and are reported with one standard deviation of the mean error bars. The exposure time was set to $6 \mathrm{~s}$ in order to ensure a sufficiently high signal to noise ratio. The sample thickness was meausured applying the log-ratio method to the elastic scattering transmittance. Since the tungsten fraction in the $\mathrm{Ni}-\mathrm{W}-\mathrm{P}$ was only small, we used the same elastic mean free path for $\mathrm{Ni}-\mathrm{P}$ and Ni-W-P: $40 \mathrm{~nm}$ [30]. The samples had an electron transmission rate of 50 to $60 \%$, thin enough for FEM [31].

TEM studies of microstructures were conducted using a Tecnai F30 ST transmission electron microscope $(300 \mathrm{kV}, \mathrm{FEI})$ with a point resolution of $0.2 \mathrm{~nm}$ and an information resolution limit of $0.14 \mathrm{~nm}$. The XEDS system of this instrument, combined with STEM nanoprobe capability providing a spatial resolution of about $2 \mathrm{~nm}$, was used to study the elemental distribution in amorphous and crystalline phases.

\section{Results}

Figure 1 shows DSC data of $\mathrm{Ni}_{0.80} \mathrm{P}_{0.20}$ and $\mathrm{Ni}_{0.76} \mathrm{~W}_{0.04} \mathrm{P}_{0.20}$ obtained at a heating rate of $\kappa=$ $0.33 \mathrm{~K} / \mathrm{s}$. Each curve exhibits one peak indicating an exothermal reaction - corresponding to the crystallization of amorphous $\mathrm{Ni}_{0.80} \mathrm{P}_{0.20}$ and $\mathrm{Ni}_{0.76} \mathrm{~W}_{0.04} \mathrm{P}_{0.20}$. The integrated peak height reflects 
the total heat of the corresponding reaction - crystallization in this case. Comparing the integrals

$$
\int \dot{Q} \mathrm{~d} t=\int \frac{\dot{Q}}{\kappa} \mathrm{d} T
$$

of the peaks, where $\kappa=\frac{\mathrm{d} T}{\mathrm{~d} t}$, indicates that the heat of crystallization is $\approx 1.5$ times lower for $\mathrm{Ni}_{0.76} \mathrm{~W}_{0.04} \mathrm{P}_{0.20}$ than for $\mathrm{Ni}_{0.80} \mathrm{P}_{0.20}$.

The peak in the curve from $\mathrm{Ni}_{0.80} \mathrm{P}_{0.20}$ corresponds to eutectic crystallization, forming $\mathrm{Ni}$ and $\mathrm{Ni}_{3} \mathrm{P}$. However, since a Ni-W-P ternary phase diagram is not available, the single exothermal peak in the curve from $\mathrm{Ni}_{0.76} \mathrm{~W}_{0.04} \mathrm{P}_{0.20}$ cannot simply be assigned to a corresponding eutectic reaction: In principle, it is possible that several reactions happen within the relevant temperature- and time intervals. At the employed heating rate, $\mathrm{Ni}_{0.76} \mathrm{~W}_{0.04} \mathrm{P}_{0.20}$ has a crystallization temperature of $687 \mathrm{~K}$, about $45 \mathrm{~K}$ higher than that of $\mathrm{Ni}_{0.80} \mathrm{P}_{0.20}, 642 \mathrm{~K}$. This is consistent with a previous study on Ni-W-P alloys with about 4 at.\% W and $18-20$ at.\% P [32], although inconsistent with other studies $[33,34]$ in which several or one broad exothermal peak at lower temperatures were observed. Variations in peak position and shape originate from slight local variation of the chemical composition due to limited control of plating conditions and corresponding slight local variation of the atomistic structure before crystallization.

Figure 2a presents X-ray diffractograms of as-plated $\mathrm{Ni}_{0.80} \mathrm{P}_{0.20}$ and $\mathrm{Ni}_{0.76} \mathrm{~W}_{0.04} \mathrm{P}_{0.20}$ alloys. XRD captures the average SRO. Accordingly, both samples were amorphous. The positions and widths of the broad peaks characterizing XRD patterns are "finger prints" of the SRO. By isolating the total diffraction response from the instrumental background, one can obtain the PDF by Fourier transformation. Since the same experimental conditions were used to acquire XRD patterns of as-received $\mathrm{Ni}_{0.80} \mathrm{P}_{0.20}$ and $\mathrm{Ni}_{0.76} \mathrm{~W}_{0.04} \mathrm{P}_{0.20}$, and the tungsten fraction of the $\mathrm{Ni}_{0.76} \mathrm{~W}_{0.04} \mathrm{P}_{0.20}$ was small, the instrumental background can be considered the same for both conditions. The similarity of diffractograms in the laboratory-source X-ray data, therefore, suggests nearly identical PDFs for both alloys, i. e. very similar average nearest-neighbor configurations.

XPS data of as-plated and tempered $\mathrm{Ni}_{0.76} \mathrm{~W}_{0.04} \mathrm{P}_{0.20}$, shown in Fig. 3, indicate the core-level binding energies of Ni-2p, P-2p, and W-4f for AR-W, T09-W, and T24-W. A comparable XPS study of tempered $\mathrm{Ni}_{0.80} \mathrm{P}_{0.20}$ is published in [29]. The binding energies of Ni-2p $3 / 2$ are all $852.9 \mathrm{eV}$, close to those of $\mathrm{Ni}_{0.80} \mathrm{P}_{0.20}(852.8 \mathrm{eV}, 852.8 \mathrm{eV}$, and $852.7 \mathrm{eV}$, respectively). The corresponding P-2p 3/2 binding energies are all $129.6 \mathrm{eV}$, also similar to those of $\mathrm{Ni}_{0.80} \mathrm{P}_{0.20}(129.6 \mathrm{eV}, 129.6 \mathrm{eV}$, 
and $129.4 \mathrm{eV}$, respectively). The binding energies of $\mathrm{W}-4 \mathrm{f} 7 / 2$ are all $31.6 \mathrm{eV}$, consistent with those of metallic tungsten reported in literature [35]. The spectra indicate that tungsten-alloying-induced energy shifts of core electron levels in $\mathrm{Ni}$ and phosphorus are no larger than the error limits of the measurements: $\approx 0.2 \mathrm{eV}$. Moreover, crystallization does not induce core-level electron energy shifts of Ni, phosphorus, or tungsten. Since core-level binding energy shifts mainly originate from changes in nearest-neighbor interaction, altering core screening, the absence of (significant) peak shifts suggests that alloying 4 at\% tungsten does not considerably change the statistical next-neighbor coordination of Ni- nor phosphorus atoms. Moreover, the crystallization process of both $\mathrm{Ni}_{0.80} \mathrm{P}_{0.20}$ and $\mathrm{Ni}_{0.76} \mathrm{~W}_{0.04} \mathrm{P}_{0.20}$ does not change the average atomistic environment of $\mathrm{Ni}$, phosphorus, and tungsten. The XPS results are consistent with the XRD results.

Figure 4 shows $V[\boldsymbol{k}]$ for as-plated as well as for tempered $\mathrm{Ni}_{0.80} \mathrm{P}_{0.20}$ and $\mathrm{Ni}_{0.76} \mathrm{~W}_{0.04} \mathrm{P}_{0.20}$. The backgrounds of the curves were stripped by subtracting fitted Lorentz function. The filled areas around the curves correspond to the standard deviations over all sampling areas. Three peaks, located at $4.8 \mathrm{~nm}^{-1}, 6.7 \mathrm{~nm}^{-1}$, and $8.3 \mathrm{~nm}^{-1}$, are observed for all these alloys. The sharp peak at about $6.7 \mathrm{~nm}^{-1}$, present in each curve, probably originates from electron diffraction at a nanocrystalline surface layer of $\mathrm{NiO}$ oxide (space group: $\mathrm{Fm} \overline{3} \mathrm{~m}$ ). This is plausible for two reasons: (1) Deleting the nano-diffraction patterns containing spots with six-fold rotational symmetry (Fig. 5a) would result in a sharp drop of this peak height, while the other peaks are not influenced. (2) The spots with six-fold rotational symmetry show good match with the diffraction pattern expected from $\mathrm{NiO}$ for a $\langle 111\rangle$ viewing direction, seen Fig. 5b. The hypothetical NiO layer was probably formed after final thinning of the TEM samples by electro-polishing. Deleting such patterns does not influence the variance values at other $\boldsymbol{k}$. The hypothetical $\mathrm{NiO}$ layer has an average thickness of only about $2 \mathrm{~nm}$, determined by XPS using in situ Ar sputtering with a known sputter rate of $1.6 \mathrm{~nm} / \mathrm{min}$. Therefore, the presence of the hypothetical $\mathrm{NiO}$ layer does not interfere the analysis of $\mathrm{MRO}$ in $\mathrm{Ni}_{0.80} \mathrm{P}_{0.20}$ and $\mathrm{Ni}_{0.76} \mathrm{~W}_{0.04} \mathrm{P}_{0.20}$.

For amorphous $\mathrm{Ni}_{0.80} \mathrm{P}_{0.20}$ and $\mathrm{Ni}_{0.76} \mathrm{~W}_{0.04} \mathrm{P}_{0.20}$, the well-developed major peak at $4.8 \mathrm{~nm}^{-1}$ as well as the weak peak at about $8.3 \mathrm{~nm}^{-1}$ concur with a published calculation of $V[\boldsymbol{k}]$ for $\mathrm{Ni}_{0.80} \mathrm{P}_{0.20}$ as metallic glass [21]. In that work, the formation of these peaks was interpreted as the ordering of quasi-equivalent TTP $\mathrm{Ni}_{9} \mathrm{P}$ clusters and the fluctuations accompanying such ordering [12, 21]. The position of the major peak is related to the nearest neighbor distance, and the nearly constant peak 
at $4.8 \mathrm{~nm}^{-1}$ confirms that neither alloying 4 at\% tungsten nor tempering significantly changes the average atomistic nearest-neighbor configuration.

The diffraction intensity variances of as-plated and those of tempered $\mathrm{Ni}_{0.76} \mathrm{~W}_{0.04} \mathrm{P}_{0.20}$ alloys are larger than those of corresponding $\mathrm{Ni}_{0.80} \mathrm{P}_{0.20}$ alloys. A higher variance indicates a larger structure fluctuation among regions within the typical sampling volume $\omega=r^{2} \cdot t$ provided by the electron microprobe diameter of $2 r \approx 2 \mathrm{~nm}$ and the specimen thickness of $t \lesssim 30 \mathrm{~nm}$. In other words, higher diffraction variance implies higher MRO.

During tempering, the maximum variance of amorphous $\mathrm{Ni}_{0.80} \mathrm{P}_{0.20}$ first decreases from $(4.6 \pm$ $0.5) \times 10^{-3}$ for as-plated $\mathrm{Ni}_{0.80} \mathrm{P}_{0.20}$ to $(2.4 \pm 0.3) \times 10^{-3}$ for $\mathrm{Ni}_{0.80} \mathrm{P}_{0.20}$ tempered $0.9 \mathrm{ks}$ at $598 \mathrm{~K}$ (remaining completely amorphous). The drop of variance indicates that brief tempering relaxes the initial amorphous structure of $\mathrm{Ni}_{0.80} \mathrm{P}_{0.20}$ into a less-ordered one. Extended tempering, $1.5 \mathrm{ks}$ at $598 \mathrm{~K}$, increases the variance to $(3.6 \pm 0.3) \times 10^{-3}$. At this stage, the $\mathrm{Ni}_{0.80} \mathrm{P}_{0.20}$ is partially crystalline. This variance increase indicates a corresponding increase of MRO, correlated with absorption of thermal energy. In addition to the major peak, Fig. 6 indicates two further peaks from the residual amorphous phase, which are located at $\approx 3.9 \mathrm{~nm}^{-1}$ and $\approx 5.7 \mathrm{~nm}^{-1}$ according to Gauß function fitting. (Gauß functions were chosen as generally good fitting functions for peaks, not to imply any physical model.) The corresponding regions are considered as nuclei of $\mathrm{Ni}_{3} \mathrm{P}$ and $\mathrm{Ni}$ in the amorphous matrix [21], respectively, although calculations predict the peak corresponding to $\mathrm{Ni}_{3} \mathrm{P}$ to occur at $\approx 3.3 \mathrm{~nm}^{-1}$. The difference between theoretical and experimental peak position probably arises from differences between the atomistic structure of the nuclei and that of the final ordered crystal. Or they may arise from differences in strain state, brought about by the surrounding amorphous matrix. The simultaneous nucleation of $\mathrm{Ni}_{3} \mathrm{P}$ and $\mathrm{Ni}$ confirms that the crystallization of amorphous $\mathrm{Ni}_{0.80} \mathrm{P}_{0.20}$ occurs close to the the eutectic composition.

In comparison, the maximum variance of as-plated amorphous $\mathrm{Ni}_{0.76} \mathrm{~W}_{0.04} \mathrm{P}_{0.20}$ slightly increases from $(6.3 \pm 0.5) \times 10^{-3}$ for as-plated material to $(6.6 \pm 0.6) \times 10^{-3}$ and $(6.8 \pm 0.5) \times 10^{-3}$ for $650 \mathrm{~K}$ $0.9 \mathrm{ks}$ and $1.5 \mathrm{ks}$ tempered $\mathrm{Ni}_{0.76} \mathrm{~W}_{0.04} \mathrm{P}_{0.20}$ alloys, respectively. No structural relaxation is observed.

The crystallization products of $\mathrm{Ni}_{0.76} \mathrm{~W}_{0.04} \mathrm{P}_{0.20}$ were identified by XRD, Fig. 2b. Accordingly, crystallization of $\mathrm{Ni}_{0.76} \mathrm{~W}_{0.04} \mathrm{P}_{0.20}$ forms $\mathrm{Ni}$ and tetragonal $\mathrm{Ni}_{3} \mathrm{P}$ (space group: $\mathrm{I} \overline{4}$ ). However, the XRD pattern also shows peaks that cannot be attributed to these two phases. The origin of these 
peaks is subject to controversy. Some researchers proposed the extra peaks to originate from metastable single-phase $\mathrm{Ni}_{12} \mathrm{P}_{5}$ [36] or $\mathrm{Ni}_{5} \mathrm{P}_{2}$ [37], respectively. Others [33], in contrast, proposed that the peaks originate from two distinct phases, $\mathrm{Ni}_{5} \mathrm{P}_{2}$ and NiP. By combining XRD with TEM, we confirm here that the extra peaks originate from a single phase: $\mathrm{Ni}_{3} \mathrm{P}$ with a hexagonal structure (metastable). However, determining the atom positions in the unit cell is beyond the scope of this paper. Based on the XRD pattern, we conclude that metastable hexagonal and stable tetragonal $\mathrm{Ni}_{3} \mathrm{P}$ form simutaneously. This means that stable tetragonal $\mathrm{Ni}_{3} \mathrm{P}$ can form directly from amorphous $\mathrm{Ni}_{0.76} \mathrm{~W}_{0.04} \mathrm{P}_{0.20}$. Metastable hexagonal $\mathrm{Ni}_{3} \mathrm{P}$ does not necessarily form during crystallization of amorphous $\mathrm{Ni}-\mathrm{P}$ or $\mathrm{Ni}-\mathrm{W}-\mathrm{P}$. Its appearance strongly depends on plating parameters, which influence details of the resulting atomistic structure.

By comparing the peaks of $\mathrm{Ni}$ and tetragonal $\mathrm{Ni}_{3} \mathrm{P}$ in XRD patterns of $\mathrm{Ni}_{0.80} \mathrm{P}_{0.20}$ and $\mathrm{Ni}_{0.76} \mathrm{~W}_{0.04} \mathrm{P}_{0.20}$, no peak shift is observed within the detection limit. The absence of tungsten-related expansion of interatomic spacings suggests that neither the forming $\mathrm{Ni}$ nor the forming tetragonal $\mathrm{Ni}_{3} \mathrm{P}$ contain significant fractions of tungsten. This is inconsistent with other studies [3, 34], which concluded that tungsten dissolves into Ni. Metastable hexagonal $\mathrm{Ni}_{3} \mathrm{P}$ has been observed by TEM [38, 39], and its lattice parameters were calculated to be $a=0.672 \mathrm{~nm}$ and $c=1.428 \mathrm{~nm}[38]$ or $a=0.656 \mathrm{~nm}$, $c=1.392 \mathrm{~nm}$ [39], respectively. Our calculation, based on the extra peaks in the XRD pattern, indicates lattice parameters $a=0.666 \mathrm{~nm}$ and $c=1.375 \mathrm{~nm}$. Based on XRD only, therefore, it is impossible to distinguish whether tungsten dissolves into the metastable hexagonal $\mathrm{Ni}_{3} \mathrm{P}$. The distribution of tungsten in the crystallized phases is further analyzed in the following, based on XEDS-STEM.

A TEM image revealing the typical microstructure of crystallized $\mathrm{Ni}_{0.76} \mathrm{~W}_{0.04} \mathrm{P}_{0.20}$ is shown in Fig 7a. Crystallites with typical diameters of several $\mu \mathrm{m}$ have formed from the amorphous matrix. Crystallites of similar size have also been observed in crystallizing $\mathrm{Ni}_{0.80} \mathrm{P}_{0.20}$. Typically, those have a spherulitic shape. The crystallized $\mathrm{Ni}_{0.76} \mathrm{~W}_{0.04} \mathrm{P}_{0.20}$, in contrast, exhibits both spherulitic and elongated crystallites. The elongated crystallites are metastable hexagonal $\mathrm{Ni}_{3} \mathrm{P}$, while the spherulites can be either stable tetragonal or metastable hexagonal $\mathrm{Ni}_{3} \mathrm{P}$. Both phases exhibit similar microstructures. The typical microstructure in one grain is shown in Fig. 7b, a conventional TEM bright-field image exhibiting diffraction contrast, i. e. regions with similar lattice orientation exhibit similar image intensity. Intensity variations within the crystallite suggest the existence of subgrains. 
Within the crystallites, nanoparticles are observed. HRTEM (high-resolution TEM) identified these as elemental $\mathrm{Ni}$ (space group: $\mathrm{Fm} \overline{3} \mathrm{~m}$ ). Often, the Ni nanoparticles contain stacking faults and/or twins, as in the example shown in Fig 7c.

Figure $8 \mathrm{a}$ and $8 \mathrm{~b}$ are the TEM bright-field image and the correponding electron diffraction pattern of a stable tetragonal $\mathrm{Ni}_{3} \mathrm{P}$ crystallite viewed in a $\langle 001\rangle$ direction, respectively. Fig 8 a reveals orientation variants of the Ni nano-platelets that make $90^{\circ}$ with each other. This is similar to the microstructure we observed in partially crystallized $\mathrm{Ni}_{0.80} \mathrm{P}_{0.20}$ [29]. Moreover, the plane spacings revealed by the spot spacings in the diffraction pattern exactly correspond to those observed in partially crystallized $\mathrm{Ni}_{0.80} \mathrm{P}_{0.20}$ [29]. This confirms our earlier conclusion based on XRD that no significant fracitons of tungsten dissolve in $\mathrm{Ni}$ or tetragonal $\mathrm{Ni}_{3} \mathrm{P}$. This conclusion is further supported by the results of XEDS-STEM. Fig 8c is a "Z-contrast" STEM image that includes the region viewed in Fig 8a. Analysis of this region by XEDS (Fig 8d) identifies the dark region (region 1) inside the grain as mainly consisting of $\mathrm{Ni}$ and phosphorus, but also containing a trace amount of tungsten. The composition is approximately $\mathrm{Ni}_{75} \mathrm{P}_{25}$, confirming the existence of $\mathrm{Ni}_{3} \mathrm{P}$ with a tungsten fraction below 1 at\%. The bright boundary layer (region 2) between the dark regions contains $\mathrm{Ni}$, phosphorus, and tungsten. Compared to the dark regions, this region is rich in tungsten. The amorphous matrix region (region 3) contains $\mathrm{Ni}$, phosphorus and tungsten, with a composition similar to the average composition detected by SEM-XEDS at lower spatial resolution. Combining these observations leads to the conclusion that tungsten segregates during crystallization, forming tungsten-free $\mathrm{Ni}_{3} \mathrm{P}$ regions and tungsten-rich boundary layers between them. The tungsten-rich regions do not contribute significant diffraction intensity. Similar characteristics are observed in the hexagonal $\mathrm{Ni}_{3} \mathrm{P}$ grains.

Moreover, XEDS spectra were acquired in different amorphous regions, and similar tungsten concentrations were obtained everywhere. With the given accuracy for quantifying elemental fractions by XEDS $(\approx 1$ at\% $)$ and the given lateral resolution $(2 \mathrm{~nm})$ and TEM foil thickness $(\approx 30 \mathrm{~nm})$, the distribution of tungsten in the amorphous state appears to be perfectly uniform. Therefore, we assume that the distribution of tungsten in amorphous $\mathrm{Ni}_{0.76} \mathrm{~W}_{0.04} \mathrm{P}_{0.20}$ is uniform down to the atomistic length scale. 


\section{Discussion}

The crystallization of amorphous $\mathrm{Ni}_{0.76} \mathrm{~W}_{0.04} \mathrm{P}_{0.20}$ has two aspects: energetics and kinetics. The observed difference in the heat (2) of crystallization reveals that the presence of tungsten reduces the energetic advantage of the crystalline phases compared to the amorphous state.

The impact of tungsten on the crystallization kinetics can be understood by a careful analysis of the microscopic mechanism of crystallization. In amorphous $\mathrm{Ni}_{0.80} \mathrm{P}_{0.20}$, according to a previous study, the structure unit is equivalent to a $\mathrm{Ni}_{9} \mathrm{P}$ TTP $[10,12]$, as shown in Fig 9a. An important key to understand the observed effects of tungsten alloying, therefore, is how tungsten changes this structural unit in the as-electroless-plated amorphous structure. The XPS data indicate that statistically - the atoms in amorphous $\mathrm{Ni}_{0.80} \mathrm{P}_{0.20}$ and amorphous $\mathrm{Ni}_{0.76} \mathrm{~W}_{0.04} \mathrm{P}_{0.20}$ have a similar environment of nearest neighbor atoms. The TEM and XEDS-STEM data presented earlier suggest that tungsten atoms are uniformly distributed down to nanometer length scale. Therefore, we hypothesize that tungsten is initially distributed in the most uniform way possible: by substituting for $\mathrm{Ni}$ in the $\mathrm{Ni}_{9} \mathrm{P}$ TTPs. This hypothesis also makes physical sense considering the coordination of phosphorus. In general, amorphous metal-metalloid alloys have strong SRO with atomistic structures similar to those of the corresponding crystalline phases. Applying this principle to a hypothetical amorphous $\mathrm{W}_{0.80} \mathrm{P}_{0.20}$, its structure unit would correspond to the tetragonal dodecahedron $\mathrm{W}_{8} \mathrm{P}$ shown in Fig 9b, which is the structure unit of crystalline $\mathrm{W}_{3} \mathrm{P}$ (space group: $\mathrm{I} \overline{4} 2 \mathrm{~m}$ ) [40].

However, the atomistic environment of phosphorus in the $\mathrm{Ni}_{9} \mathrm{P}$ TTP and the $\mathrm{W}_{8} \mathrm{P}$ tetragonal dodecahedron are different. Therefore, if the structural unit of amorphous $\mathrm{Ni}_{0.76} \mathrm{~W}_{0.04} \mathrm{P}_{0.20}$ actually were the $\mathrm{W}_{8} \mathrm{P}$ tetragonal dodecahedron, one would expect a corresponding "chemical shift" of the phosphorus $2 \mathrm{p}$ binding energy in XPS spectra. However, we did not observe that. Since the tungsten fraction is only 4 at\%, most structure units may contain no more than one tungsten atom, corresponding to a composition of $\mathrm{Ni}_{8} \mathrm{WP}$. Apparently, this level of Ni substitution by tungsten is not sufficiently high to favor the $\mathrm{W}_{8} \mathrm{P}$ tetragonal dodecahedron over a $\mathrm{Ni}_{8} \mathrm{WP}$ TTP as structure unit.

The ratio of $\mathrm{Ni}_{9} \mathrm{P}$ TTP to $\mathrm{Ni}_{8} \mathrm{WP}$ TTP in the amorphous $\mathrm{Ni}_{0.76} \mathrm{~W}_{0.04} \mathrm{P}_{0.20}$ can be estimated as follows: (1) The composition of $\mathrm{Ni}_{0.80} \mathrm{P}_{0.20}$ corresponds to a $\mathrm{Ni}: \mathrm{P}$ ratio of $4: 1$. To realize this with $\mathrm{Ni}_{9} \mathrm{P}$ clusters, neighboring clusters have to share $\mathrm{Ni}$ atoms. If all of the $\mathrm{Ni}$ atoms were shared by 2 , 
3 or $4 \mathrm{P}$ atoms, the composition would be $\mathrm{Ni}_{4.5} \mathrm{P}, \mathrm{Ni}_{3} \mathrm{P}$, or $\mathrm{Ni}_{2.25} \mathrm{P}$, respectively. Theoretically, $\mathrm{Ni}_{4} \mathrm{P}$ could combine all these conditions. Assume that out of all Ni atoms, $x_{2}, x_{3}$, and $x_{4}=9-x_{2}-x_{3}$ $\mathrm{Ni}$ atoms are shared by 2, 3, and 4 phosphorus atoms, respectively, and that these items are denoted as Ni2, Ni3, and Ni4. This leads to the following condition for $x_{2}, x_{3}$ :

$$
\mid \wedge \begin{aligned}
\frac{1}{2} x_{2}+\frac{1}{3} x_{3}+\frac{1}{4}\left(9-x_{2}-x_{3}\right) & =4 \\
x_{2}+y_{3} & \leq 9
\end{aligned} .
$$

Solutions include $\left(x_{2}=6, x_{3}=3,9-x_{2}-x_{3}=0\right)$ or $\left(x_{2}=7, x_{3}=0,9-x_{2}-x_{3}=2\right)$. In other words, one $\mathrm{Ni}_{9} \mathrm{P}$ cluster may consist of $6 \mathrm{Ni} 2$ and $3 \mathrm{Ni} 3$ atoms, wheras another such cluster consists of $7 \mathrm{Ni} 2$ and $2 \mathrm{Ni} 4$ atoms. A large number of $\mathrm{Ni}_{9} \mathrm{P}$ clusters will probably contain a combination of these two variants. (2) The composition of $\mathrm{Ni}_{0.76} \mathrm{~W}_{0.04} \mathrm{P}_{0.20}$ corresponds to a Ni:W:P ratio of 3.8:0.2:1. If all of the tungsten atoms substitute $\mathrm{Ni2}, \mathrm{Ni3}$ or Ni4, the tungsten fraction $X_{\mathrm{W}}$ should satisfy the relations

$$
\begin{aligned}
& \frac{\frac{1}{2} X_{\mathrm{W}}}{\frac{1}{2}\left(6-X_{\mathrm{W}}\right)+\frac{1}{3} \cdot 3}=\frac{0.2}{3.8}, \\
& \frac{\frac{1}{3} X_{\mathrm{W}}}{\frac{1}{3}\left(3-X_{\mathrm{W}}\right)+\frac{1}{2} \cdot 6}=\frac{0.2}{3.8}, \\
& \frac{\frac{1}{4} X_{\mathrm{W}}}{\frac{1}{4}\left(2-X_{\mathrm{W}}\right)+\frac{1}{2} \cdot 7}=\frac{0.2}{3.8},
\end{aligned}
$$

respectively. The solutions are $X_{\mathrm{W}}=0.4, X_{\mathrm{W}}=0.6$, and $X_{\mathrm{W}}=0.8$, respectively. In other words, if all tungsten atoms substituted for $\mathrm{Ni} 2, \mathrm{Ni} 3$, or $\mathrm{Ni} 4$, there would be $40 \%, 60 \%$, or $80 \% \mathrm{Ni}_{8} \mathrm{WP}$ clusters in amorphous $\mathrm{Ni}_{0.76} \mathrm{~W}_{0.04} \mathrm{P}_{0.20}$, respectively. As all these substitutions are possible, the fraction of $\mathrm{Ni}_{8} \mathrm{WP}$ clusters will range between $40 \%$ and $80 \%$.

Now consider the spatial arrangement of $\mathrm{Ni}_{8} \mathrm{WP}$ and $\mathrm{Ni}_{9} \mathrm{P}$ TTP clusters. Based on our FEM study, amorphous $\mathrm{Ni}_{0.76} \mathrm{~W}_{0.04} \mathrm{P}_{0.20}$ has a similar $V[\boldsymbol{k}, R]$ as amorphous $\mathrm{Ni}_{0.80} \mathrm{P}_{0.20}$. The peak at $\approx 4.8 \mathrm{~nm}^{-1}$ in $V[\boldsymbol{k}, R]$ of $\mathrm{Ni}_{0.80} \mathrm{P}_{0.20}$ corresponds to the icosahedral arrangement of quasi-equivalent $\mathrm{Ni}_{9} \mathrm{P}$ TTPs [21]. This suggests that the arrangement of $\mathrm{Ni}_{8} \mathrm{WP}$ and $\mathrm{Ni}_{9} \mathrm{P}$ TTPs also has icosahedral features. Since the atomic radius of tungsten, $0.137 \mathrm{~nm}$, is larger than that of $\mathrm{Ni}$ atom, $0.125 \mathrm{~nm}$ [41], the volume of $\mathrm{Ni}_{8} \mathrm{WP}$ is expected to be larger than that $\mathrm{Ni}_{9} \mathrm{P}$. Therefore, the icosahedral arrangement of $\mathrm{Ni}_{8} \mathrm{WP}$ and $\mathrm{Ni}_{9} \mathrm{P}$ clusters will accomplish more complete space filling than the arrangement of just $\mathrm{Ni}_{9} \mathrm{P}$ clusters. This implies less free volume available for diffusion and therefore slower crystallization kinetics. 
The change in details of the atomistic structure and stability is just one effect of tungsten alloying. Another important aspect is chemical bonding. It is known that amorphous $\operatorname{Pd}_{0.40} \mathrm{Ni}_{0.40} \mathrm{P}_{0.20}$ is a good glass former, and its crystallization can be retarded to about $678 \mathrm{~K}$ at a heating rate of $0.33 \mathrm{~K} / \mathrm{s}[25]$. However, compared to amorphous $\mathrm{Ni}_{0.76} \mathrm{~W}_{0.04} \mathrm{P}_{0.20}$, the retarding efficiency is not high. Already 4 at\% tungsten retard the crystallization to about $687 \mathrm{~K}$ at the same heating rate. $\mathrm{Pd}$ and tungsten have nearly the same atom radius [41]. Accordingly, different efficacies in retarding crystallization cannot be explained simply by steric aspects. Calculations based on the Miedema model indicate that $\mathrm{Pd}$ has smaller heat of mixing with phosphorus, $-36.5 \mathrm{~kJ} / \mathrm{mol}$, than tungsten has with phosphorus, $-46.5 \mathrm{~kJ} / \mathrm{mol}[41]$. This suggests that $\mathrm{W}-\mathrm{P}$ bonds are stronger than $\mathrm{Pd}-\mathrm{P}$ bonds. Since crystallization requires breaking bonds, stronger bonds stabilize the amorphous state to higher temperatures.

A third important aspect is the electron configuration of the alloying element, as it will impact the atomistic structure of $\mathrm{P}$-centered clusters in amorphous $\mathrm{Ni}_{0.80} \mathrm{P}_{0.20}$ (or amorphous metal-metalloid alloys in general). For example, $\mathrm{Ni}$ and $\mathrm{Pd}$ belong to the same group of the periodic table and form similar P-centered clusters - $\mathrm{Ni}_{9} \mathrm{P}$ and $\mathrm{Pd}_{9} \mathrm{P}$ TTPs, respectively. Tungsten and Mo are in the same group and have similar atomic radii as $\mathrm{Pd}$, and in crystalline $\mathrm{W}_{3} \mathrm{P}$ and $\mathrm{Mo}_{3} \mathrm{P}$, they form $\mathrm{W}_{8} \mathrm{P}$ and $\mathrm{Mo}_{8} \mathrm{P}$ tetragonal dodecahedra, respectively. $\mathrm{Cu}$, which has a similar atomic radius as $\mathrm{Ni}$, forms $\mathrm{Cu}_{8} \mathrm{P}$ tetragonal dodecahedra in crystalline $\mathrm{Cu}_{3} \mathrm{P}$. The fact that $\mathrm{Pd}-\mathrm{Ni}-\mathrm{Cu}-\mathrm{P}$ has even better GFA than Pd-Ni-P has been interpreted as a result of co-existence between TTPs and tetragonal dodecahedron clusters instead of just TTPs in Pd-Ni-P [26]. This theory suggests that a higher level of tungsten alloying, enabling the formation of $\mathrm{Ni}_{8-\mathrm{x}} \mathrm{W}_{\mathrm{x}} \mathrm{P}$ tetragonal dodecahedra in addition to TTPs, would further stabilize the amorphous structure and retard the crystallization to even higher temperatures. (However, the limit of this approach will be reached at alloying levels at which most structure units become tetragonal dodecahedra.) In a similar way, co-plating a fourth element that could form structure units other than TTPs could also have a strong effect on stablizing the amorphous structure.

Considering the above three aspects, we are able to explain why structure relaxation was observed in as-plated amorphous $\mathrm{Ni}_{0.80} \mathrm{P}_{0.20}$, but not in as-plated amorphous $\mathrm{Ni}_{0.76} \mathrm{~W}_{0.04} \mathrm{P}_{0.20}$. The different response to tempering suggests that the atomistic structure of $\mathrm{Ni}_{0.76} \mathrm{~W}_{0.04} \mathrm{P}_{0.20}$ is more stable than that of $\mathrm{Ni}_{0.80} \mathrm{P}_{0.20}$. Alloying tungsten to amorphous $\mathrm{Ni}_{0.80} \mathrm{P}_{0.20}$ results in the formation of $\mathrm{Ni}_{8} \mathrm{WP}$ 
TTPs units in addition to $\mathrm{Ni}_{9} \mathrm{P}$ TTP $[\mathrm{s}]$. Also, the volume of $\mathrm{Ni}_{8}$ WP TTPs provides denser packing, hindering the rearrangement of clusters that is required for crystallization. Moreover, owing to the electron configuration of tungsten, $\mathrm{W}-\mathrm{P}$ bonds are stronger than $\mathrm{Ni}-\mathrm{P}$ bonds, and $\mathrm{W}-\mathrm{Ni}$ bonds are stronger than $\mathrm{Ni}-\mathrm{Ni}$ bonds [41]. Therefore, the presence of tungsten impedes the breaking of interatomic bonds required for crystallization.

The model developed here also applies to amorphous $\mathrm{Ni}_{0.80} \mathrm{P}_{0.20}$ alloyed with Mo. Mo has a similar atomic radius as tungsten $(0.136 \mathrm{~nm}$ vs $0.137 \mathrm{~nm})$. Mo-P has an even more negative heat of mixing than of $\mathrm{W}-\mathrm{P}(-53.5 \mathrm{~kJ} / \mathrm{mol}$ vs $(-46.5 \mathrm{~kJ} / \mathrm{mol})$. Mo and tungsten have similar electronic structure. Therefore, Mo is expected to have a similar or even better retarding effect on the crystallization of $\mathrm{Ni}_{0.80} \mathrm{P}_{0.20}$.

A more complex structure of the crystallizing phases will likely kinetically inhibit the rate of crystallization. Crystallization of amorphous $\mathrm{Ni}_{0.80} \mathrm{P}_{0.20}$ yields crystalline $\mathrm{Ni}$ and $\mathrm{Ni}_{3} \mathrm{P}$, whereas the crystallization of amorphous $\mathrm{Ni}_{0.76} \mathrm{~W}_{0.04} \mathrm{P}_{0.20}$ involves the segregation of tungsten in addition to the formation of $\mathrm{Ni}$ and $\mathrm{Ni}_{3} \mathrm{P}$. Different from $\mathrm{Ni}_{0.80} \mathrm{P}_{0.20}$, therefore, the crystallization of $\mathrm{Ni}_{0.76} \mathrm{~W}_{0.04} \mathrm{P}_{0.20}$ includes breaking $\mathrm{Ni}-\mathrm{Ni}, \mathrm{Ni}-\mathrm{W}, \mathrm{Ni}-\mathrm{P}$, and $\mathrm{W}-\mathrm{P}$ bonds as well as rearrangement of $\mathrm{Ni}_{9} \mathrm{P}$ and $\mathrm{Ni}_{8} \mathrm{WP}$ clusters.

\section{Conclusions}

The conclusion of our analysis is that alloying tungsten to amorphous $\mathrm{Ni}_{0.80} \mathrm{P}_{0.20}$ retards crystallization because (i) the presence of tungsten reduces the driving force for crystallization and (ii) tungsten slows the kinetics of crystallization. The amorphous state is stabilized by tungsten for the following reasons: Alloying tungsten introduces $\mathrm{Ni}_{8}$ WP TTP clusters in addition to the $\mathrm{Ni}_{9} \mathrm{P}$ TTP clusters present in $\mathrm{Ni}_{0.80} \mathrm{P}_{0.20}$. These clusters arrange themselves in an icosahedral configuration similar to the arrangement of just $\mathrm{Ni}_{9} \mathrm{P}$ TTP clusters, but they are larger and provide for a higher degree of space filling, thus reducing the free volume available for diffusion. In addition, the presence of tungsten introduces $\mathrm{W}-\mathrm{P}$ and $\mathrm{W}-\mathrm{Ni}$ bonds, which are stronger than $\mathrm{Ni}-\mathrm{P}$ and $\mathrm{Ni}-\mathrm{Ni}$ bonds, respectively. Moreover, alloying tungsten leads to a more complex crystallization products, which requires more thermal energy for bond breaking and atoms diffusion. The criteria identified in this work can be used to identify even more effective alloying elements to retard the crystallization 
of amorphous $\mathrm{Ni}_{0.80} \mathrm{P}_{0.20}$ or similar alloys. For example, alloying $\mathrm{Ni}_{0.80} \mathrm{P}_{0.20}$ with Mo or Mo and tungsten (e.g. by co-plating) is predicted to be more efficient than alloying with (just) tungsten. These observations can be generalized to analyze the stability of other amorphous metal-metalloid alloys and understand their crystallization behavior.

\section{Acknowledgment}

We acknowledge Atotech Deutschland $\mathrm{GmbH}$ for financial support and for providing samples. We thank Z Vashaei, WD Jennings, and Z Li for help with the experimental work. Fluctuation electron microscopy at the University of Wisconsin-Madison was partially supported by the U.S. National Science Foundation (DMR-1506564). Electron microscopy facilities at Wisconsin are supported by the University of Wisconsin Materials Research Science and Engineering Center (DMR-1121288). 


\section{References}

[1] J. Hajdu, S. Zabrocky, The future of electroless nickel, Metal Finishing 98 (5) (2000) 42-46. doi:10.1016/S0026-0576(00)81730-4.

[2] J. Flechon, S. Karbal, F. Machizaud, Magnetization of an electroless deposited Nickel-Phosphorus alloy, Journal de Physique 46 (1985) 1405-1409. doi:10.1051/jphys:019850046080140500.

[3] S. B. Antonelli, T. L. Allen, D. C. Johnson, V. M. Dubin, Determining the role of w in suppressing crystallization of electroless Ni-W-P films, Journal of The Electrochemical Society 153 (6) (2006) J46. doi:10.1149/1.2193332.

[4] I. Ohno, Electroless deposition of alloys, in: M. Schlesinger, M. Paunovic (Eds.), Modern Electroplating, 5th Edition, Wiley, 2010, pp. 499-506. doi:10.1002/9780470602638.ch22.

[5] G. S. Cargill, Dense random packing of hard spheres as a structural model for noncrystalline metallic solids, Journal of Applied Physics 41 (1970) 2248-2250.

[6] J. D. Bernal, Geometry of the structure of monatomic liquids, Nature 185 (1960) 68-70.

[7] D. E. Polk, Structural model for amorphous metallic alloys, Scripta Metallurgica 4 (2) (1970) $117-122$.

[8] T. M. Hayes, J. W. Allen, Short-range order in metallic glasses, Phys. Rev. Lett. 40 (19) (1978) 1282.

[9] J. W. Allen, A. C. Wright, G. A. N. Connell, Hybridization, short range order, and entropy in metallic glass formation, Journal of Non-Crystalline Solids 42 (1-3) (1980) 509-524. doi:doi:10.1016/0022-3093(80)90049-6.

[10] P. H. GASKELL, A new structural model for transition metal-metalloid glasses, Nature 276 (1978) 484-485. doi:10.1038/276484a0.

[11] P. Lamparter, Reverse monte carlo simulation of amorphous $\mathrm{Ni}_{80} \mathrm{P}_{20}$ and $\mathrm{Ni}_{81} \mathrm{~B}_{19}$, Physica Scripta. T57 (1995) 72-78.

[12] H. W. Sheng, W. K. Luo, F. M. Alamgir, J.M.Bai, E. Ma, Atomic packing and short-to-mediumrange order in metallic glasses, Nature 439 (2006) 419-425. doi:10.1038/nature04421. 
[13] P. M. Voyles, J. M. Gibson, M. M. J. Treacy, Fluctuation microscopy: A probe of atomic correlations in disordered materials, J Electron Microsc (Tokyo) 49 (2) (2000) 259-266.

[14] M. M. J. Treacy, J. M. Gibson, L. Fan, D. J. Paterson, I. McNulty, Fluctuation microscopy: A probe of medium range order, Rep. Prog. Phys. 68 (2005) 2899-2944.

[15] P. M. Voyles, J. R. Abelson, Medium-Range order in amorphous silicon measured by fluctuation electron microscopy, Solar Energy Materials and Solar Cells 78 (1-4) (2003) 85-113. doi:10.1016/S0927-0248(02)00434-8.

[16] J. V. Ryan, C. G. Pantano, Medium-range order in silicon oxycarbide glass by fluctuation electron microscopy, J. Phys.: Condens. Matter 19 (2007) 455205.

[17] W. G. Stratton, J. Hamann, J. H. Perepezko, P. M. Voyles, X. Mao, S. V. Khare, Aluminum nanoscale order in amorphous $\mathrm{Al}_{92} \mathrm{Sm}_{8}$ measured by fluctuation electron microscopy, App. Phys. Lett. 86 (2005) 141910. doi:10.1063/1.1897830.

[18] J. Hwang, Z. H. Melgarejo, Y. E. Kalay, I. Kalay, M. J. Kramer, D. S. Stone, P. M. Voyles, Nanoscale structure and structural relaxation in $\mathrm{Zr}_{50} \mathrm{Cu}_{45} \mathrm{Al}_{5}$ bulk metallic glass, Phys. Rev. Lett. 108 (2012) 195505. doi:http://dx.doi.org/10.1103/PhysRevLett.108.195505.

[19] P. Zhang, J. J. Maldonis, M. F. Besser, M. J. Kramer, P. M. Voyles, Medium-range structure and glass forming ability in Zr-Cu-Al bulk metallic glasses, Acta Materialia 109 (2016) 103-114. doi:10.1016/j.actamat.2016.02.006.

[20] P. M. Voyles, D. A. Muller, Fluctuation microscopy in the STEM, Ultramicroscopy 93 (2002) $147-159$.

[21] J. Wen, Y. Q. Cheng, J. Q. Wang, E. Ma, Distinguishing medium-range order in metallic glasses using fluctuation electron microscopy: A theoretical study using atomic models, Journal of Applied Physics 105 (2009) 043519. doi:10.1063/1.3079514.

[22] D. B. Miracle, A structural model for metallic glasses, Nature Materials 3 (2004) 697-702.

[23] F. M. Alamgir, H. Jain, A. C. Miller, D. B. Williams, R. B. Schwarz, X-ray photoelectron spectroscopy analysis of bulk Pd-Ni-P metallic glasses, Philosophical Magazine Part B 79 (2) (1999) 239-247. doi:10.1080/13642819908206795. 
[24] F. M. Alamgir, H. Jain, D. B. Williams, R. B. Schwarz, The structure of a metallic glass system using EXELFS and EXAFS as complementary probes, Micron 34 (8) (2003) 433-439. doi:10.1016/S0968-4328(03)00100-8.

[25] Y. He, R. B. Schwarz, J. I. Archuleta, Bulk glass formation in the Pd-Ni-P system, Appl. Phys. Lett. 69 (1996) 1861. doi:http://dx.doi.org/10.1063/1.117458.

[26] A. Inoue, Stabilization of metallic supercooled liquid and bulk amorphous alloys, Acta Materialia 48 (1) (2000) 279-306. doi:10.1016/S1359-6454(99)00300-6.

[27] S. Hosokawa, H. Sato, T. Ichitsubo, M. Nakatake, N. Happo, J.-F. Bérar, N. Boudet, T. Usuki, W.-C. Pilgrim, E. Matsubara, N. Nishiyama, Inhomogeneity and glass-forming ability in the bulk metallic glass $\mathrm{Pd}_{42.5} \mathrm{Ni}_{7.5} \mathrm{Cu}_{30} \mathrm{P}_{20}$ as seen via X-ray spectroscopies, Phys. Rev. B 80 (2009) 174204 .

[28] X. Zhan, Phase transformation and magnetic properties of Ni-W-P amorphous alloy, Dissertation, Case Western Reserve University.

[29] X. Zhan, F. Ernst, Crystallization micro-mechanism of near-eutectic amorphous Ni-P, Acta Materialia 104 (2016) 274-282. doi:10.1016/j.actamat.2015.11.005.

[30] P. Zhang, Z. Wang, J. H. Perepezko, P. Voyles, Elastic and inelastic mean free paths of $200 \mathrm{keV}$ electrons in metallic glasses, Ultramicroscopy (2016) To be published.

[31] J. Hwang, Nanometer scale atomic structure of zirconium based bulk metallic glass, Ph.D. thesis, University of Wisconsin-Madison (2011).

[32] S. B. Antonelli, T. L. Allen, D. C. Johnson, Determining the role of w in suppressing crystallization of electroless Ni-W-P films, 207 ${ }^{\text {th }}$ ECS Meeting (2005) Abstract \#343.

[33] J. N. Balaraju, Kalavati, N. Manikandanath, V. W. Grips, Phase transformation behavior of nanocrystalline Ni-W-P alloys containing various w and p contents, Surface and Coatings Technology 206 (10) (2012) 2682-2689. doi:10.1016/j.surfcoat.2011.11.024.

[34] Y. Tsai, F. Wu, Y. Chen, P. Peng, J. Duh, S. Tsai, Thermal stability and mechanical properties of Ni-W-P electroless deposits, Surface and Coatings Technology 146-147 (2001) 502-507. doi:10.1016/S0257-8972(01)01462-1. 
[35] B. Kim, J. Chen, J. L. Erskine, W. N. Mei, C. M. Wei, Surface and bulk photoelectron diffraction from W(110) 4f core levels, Phys. Rev. B 48 (1993) 4735. doi:http://dx.doi.org/10.1103/PhysRevB.48.4735.

[36] K. Konopka, M. Trzaska, D. Oleszak, W. Zielinski, K. Kurzydłowski, Studies of amorphous ni-p thin films produced by the chemical reduction method, Solid State Phenomena 94 (2003) 249-252. doi:10.4028/www.scientific.net/SSP.94.249.

[37] K. H. Hur, J. H. Jeong, D. N. Lee, Microstructures and crystallization of electroless ni-p deposits, Journal of Materials Science 25 (1990) 2573-2584.

[38] K. H. Kuo, Y. K. Wu, J. Z. Liang, Z. H. Lai, The metastable phases formed in amorphous ni-p alloys during crystallization, Philosophical Magazine A 51 (2) (1985) 205-222.

[39] T. Ikari, M. Izaki, T. Fukumori, K. Futagami, The activation energies of the crystallization of amorphous ni81p19 alloy films, Journal of Materials Science 26 (1991) 583-587.

[40] S. Rundqvist, New metal-rich phosphides of niobium, tantalum and tungsten, Nature 211 (1966) 847-848. doi:10.1038/211847a0.

[41] A. Takeuchi, A. Inoue, Classification of bulk metallic glasses by atomic size difference, heating of mixing and period of constituent elements and its application to characterization of the main alloying element, Materials Transactions 46 (2005) 2817-2829. doi:http://doi.org/10.2320/matertrans.46.2817. 


\section{Tables}

Table 1: Specimen Designations.

\begin{tabular}{|c|c|c|c|c|c|}
\hline Ni-P & Temp./K & Time / ks & Ni-W-P & Temp./K & Time / ks \\
\hline AR & - & - & AR-W & - & - \\
T09 & 598 & 0.9 & T09-W & 650 & 0.9 \\
T15 & 598 & 1.5 & T15-W & 650 & 1.5 \\
T24 & 598 & 2.4 & T24-W & 650 & 2.4 \\
\hline
\end{tabular}


Table 2: Plating Parameters of Amorphous Ni-W-P.

\begin{tabular}{|c|c|c|}
\hline Chemical & Value $/\left(\mathrm{mol} \mathrm{m}^{-3}\right)$ & Operation Conditions \\
\hline $\mathrm{NiSO}_{4} \cdot 7 \mathrm{H}_{2} \mathrm{O}$ & 37.5 & $\mathrm{pH}=9$ \\
$\mathrm{NaH}_{2} \mathrm{PO}_{4} \cdot \mathrm{H}_{2} \mathrm{O}$ & 60 & $T=368 \mathrm{~K}$ \\
Sodium Citrate & 300 & \\
$\mathrm{Na}_{2} \mathrm{WO}_{4} \cdot 2 \mathrm{H}_{2} \mathrm{O}$ & 75 & \\
\hline
\end{tabular}


Table 3: XEDS Composition Quantification of as-plated Ni-P and $\mathbf{N i}-\mathbf{W}-\mathbf{P}$.

\begin{tabular}{|c|c|c|c|}
\hline Sample & $\mathrm{Ni} /$ at. $\%$ & $\mathrm{P} /$ at. $\%$ & $\mathrm{~W} /$ at. $\%$ \\
\hline $\mathrm{Ni}-\mathrm{P}$ & $80.2 \pm 0.1$ & $19.8 \pm 0.1$ & - \\
$\mathrm{Ni}-\mathrm{W}-\mathrm{P}$ & $76.3 \pm 0.5$ & $19.9 \pm 0.5$ & $3.8 \pm 0.1$ \\
\hline
\end{tabular}




\section{Figure Legends}

1. DSC curves of $\mathrm{Ni}_{0.80} \mathrm{P}_{0.20}$ and $\mathrm{Ni}_{0.76} \mathrm{~W}_{0.04} \mathrm{P}_{0.20}$ at a heating rate of $0.33 \mathrm{~K} / \mathrm{s}$.

2. X-ray diffraction patterns of (a) As received amorphous $\mathrm{Ni}_{0.80} \mathrm{P}_{0.20}$ and $\mathrm{Ni}_{0.76} \mathrm{~W}_{0.04} \mathrm{P}_{0.20}$, (b) $\mathrm{Ni}_{0.80} \mathrm{P}_{0.20}$ and $\mathrm{Ni}_{0.76} \mathrm{~W}_{0.04} \mathrm{P}_{0.20}$ tempered at $598 \mathrm{~K}$ and $650 \mathrm{~K}$ for $2.4 \mathrm{ks}$, respectively. t-Ni ${ }_{3} \mathrm{P}$ : tetragonal $\mathrm{Ni}_{3} \mathrm{P} . \mathrm{h}-\mathrm{Ni}_{3} \mathrm{P}$ : hexagonal $\mathrm{Ni}_{3} \mathrm{P}$.

3. XPS spectra of as received, tempered at $650 \mathrm{~K} 0.9 \mathrm{ks}$ and $2.4 \mathrm{ks} \mathrm{Ni}_{0.76} \mathrm{~W}_{0.04} \mathrm{P}_{0.20}$ alloy. (a) P-2p core level. (b) Ni-2p core level. (c) W-4f core level.

4. FEM of $\mathrm{Ni}_{0.80} \mathrm{P}_{0.20}$ and $\mathrm{Ni}_{0.76} \mathrm{~W}_{0.04} \mathrm{P}_{0.20}$ alloy. (a) As received, tempered at $598 \mathrm{~K} 0.9 \mathrm{ks}$ and $1.5 \mathrm{ks} \mathrm{Ni}_{0.80} \mathrm{P}_{0.20}$ alloy. (b) As received, tempered at $650 \mathrm{~K} 0.9 \mathrm{ks}$ and $1.5 \mathrm{ks} \mathrm{Ni} \mathrm{Ni}_{0.76} \mathrm{~W}_{0.04} \mathrm{P}_{0.20}$ alloy.

5. Diffraction patterns of (a) Typical nano-diffraction pattern shown 6-fold rotational symmetry in as received and tempered $\mathrm{Ni}_{0.80} \mathrm{P}_{0.20}$ and $\mathrm{Ni}_{0.76} \mathrm{~W}_{0.04} \mathrm{P}_{0.20}$ alloy, and (b) simulated diffraction pattern of $\mathrm{NiO}\langle 111\rangle$ zone axis.

6. FEM of $\mathrm{Ni}_{0.80} \mathrm{P}_{0.20}$ in the as received condition and after tempering for $0.9 \mathrm{ks}$ and $1.5 \mathrm{ks}$ at $598 \mathrm{~K}$, respectively. The graphs show the experimentally determined variance $V[k]$ for the $k$ range between $3.2 \mathrm{~nm}^{-1}$ and $6.2 \mathrm{~nm}^{-1}$. The curve for $1.5 \mathrm{ks}$ was fitted by a superposition of three Gauß functions, denoted as "Peak 1," "Peak 2," and "Peak 3".

7. TEM bright-field images of partially crystallized $\mathrm{Ni}_{0.76} \mathrm{~W}_{0.04} \mathrm{P}_{0.20}$ alloy. (a) TEM bright-field image shown spherulite-like and elongated grains. (b) TEM bright-field image shown typical microstructure and nanoparticles (NP) in one grain. (c) HRTEM image of one nanoparticle, featuring stacking faults and twin boundaries (TB).

8. Partially crystallized nwp: TEM bright-field image, SADP (selected-area diffraction pattern), STEM image, and XEDS spectra of a tetragonal $\mathrm{Ni}_{3} \mathrm{P}$ grain (viewing direction: $\langle 001\rangle$ ). (a) TEM bright-field image, showing Ni nano-platelets that make $90^{\circ}$ with each other in the $\langle 001\rangle$ viewing direction. (b) SADP of this region. (c) STEM image showing "Z-contrast." (d) XEDS spectra from region 1 (dark), region 2 (bright), and region 3 (amorphous matrix). 
9. Structure unit in crystalline $\mathrm{Ni}_{3} \mathrm{P}$ and $\mathrm{W}_{3} \mathrm{P}$. (a) $\mathrm{Ni}_{9} \mathrm{P}$ TTP. (b) $\mathrm{W}_{8} \mathrm{P}$ tetragonal dodecahedron. 
Figures Enlarged

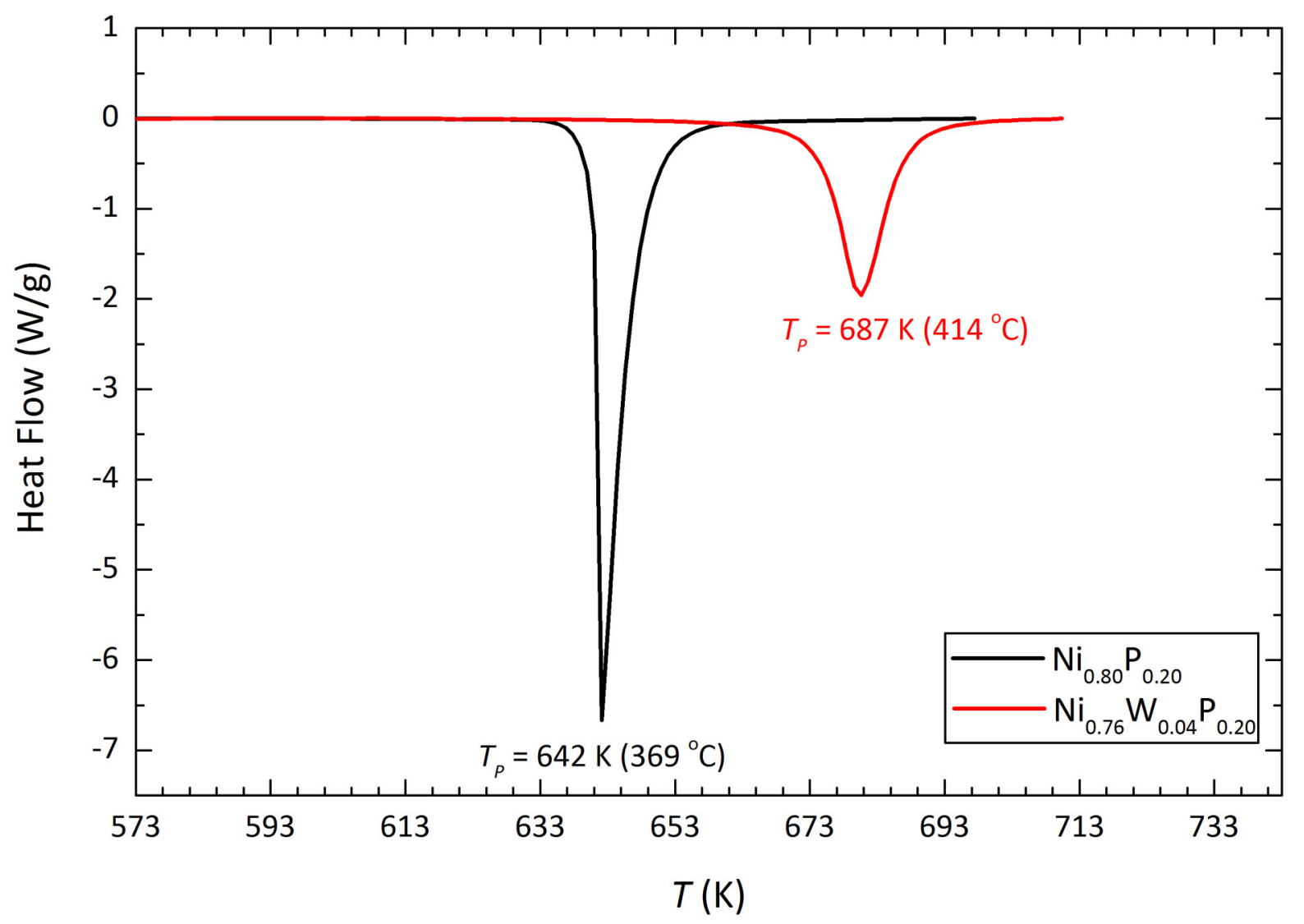

Figure 1: DSC curves of $\mathrm{Ni}_{0.80} \mathrm{P}_{0.20}$ and $\mathrm{Ni}_{0.76} \mathrm{~W}_{0.04} \mathrm{P}_{0.20}$ at a heating rate of $0.33 \mathrm{~K} / \mathrm{s}$. 

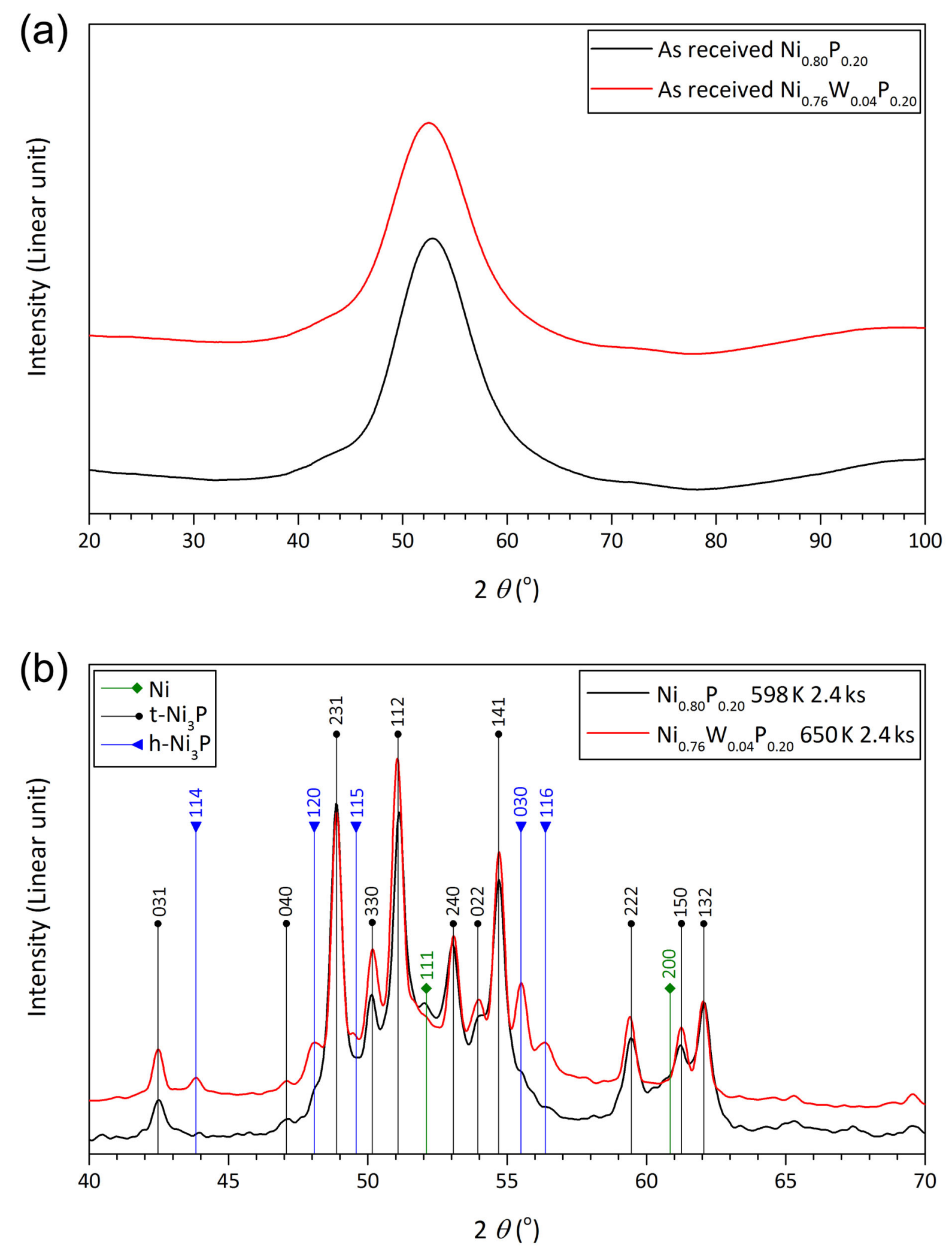

Figure 2: X-ray diffraction patterns of (a) As received amorphous $\mathrm{Ni}_{0.80} \mathrm{P}_{0.20}$ and $\mathrm{Ni}_{0.76} \mathrm{~W}_{0.04} \mathrm{P}_{0.20}$, (b) $\mathrm{Ni}_{0.80} \mathrm{P}_{0.20}$ and $\mathrm{Ni}_{0.76} \mathrm{~W}_{0.04} \mathrm{P}_{0.20}$ tempered at $598 \mathrm{~K}$ and $650 \mathrm{~K}$ for $2.4 \mathrm{ks}$, respectively. $\mathrm{t}-\mathrm{Ni}_{3} \mathrm{P}$ : tetragonal $\mathrm{Ni}_{3} \mathrm{P} . \mathrm{h}-\mathrm{Ni}_{3} \mathrm{P}$ : hexagonal $\mathrm{Ni}_{3} \mathrm{P}$. 

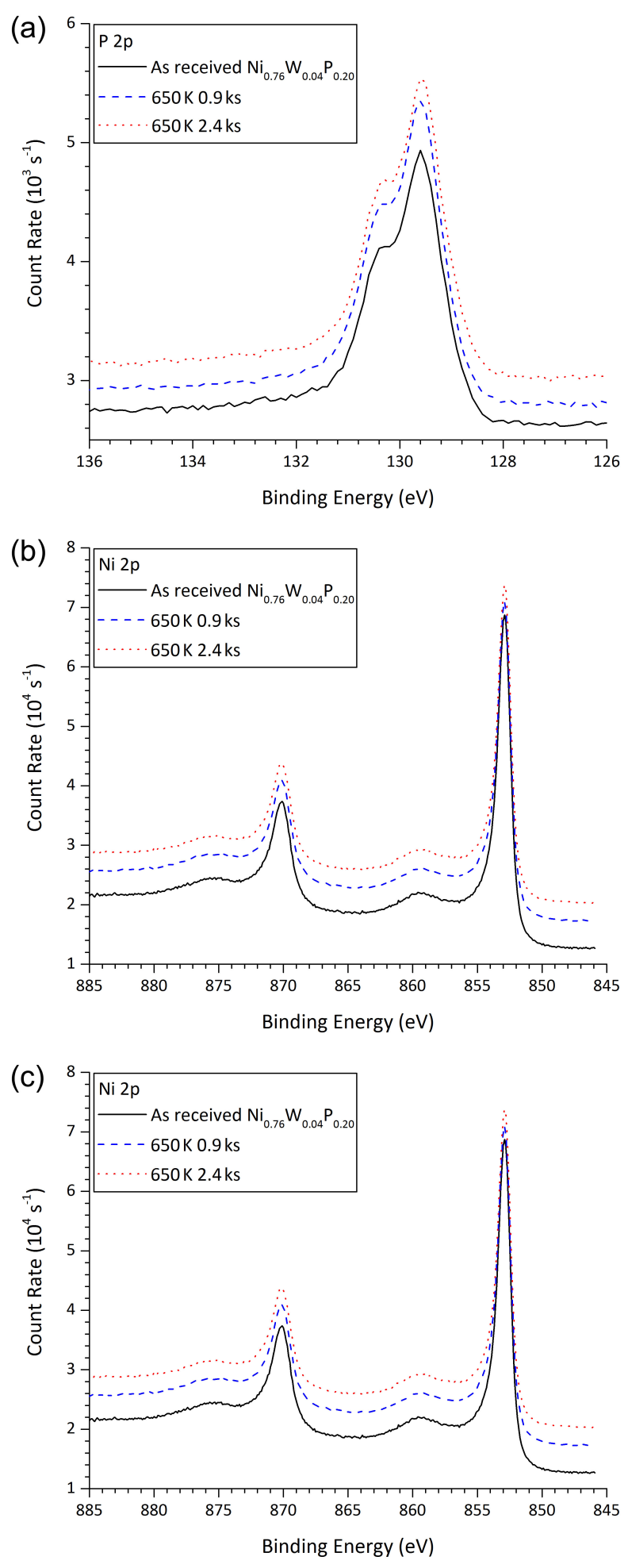

Figure 3: XPS spectra of as received, tempered at $650 \mathrm{~K} 0.9 \mathrm{ks}$ and2.4 $\mathrm{ks} \mathrm{Ni} 0.76 \mathrm{~W}_{0.04} \mathrm{P}_{0.20}$ alloy. (a) P-2p core level. (b) Ni-2p core level. (c) W-4f core level. 

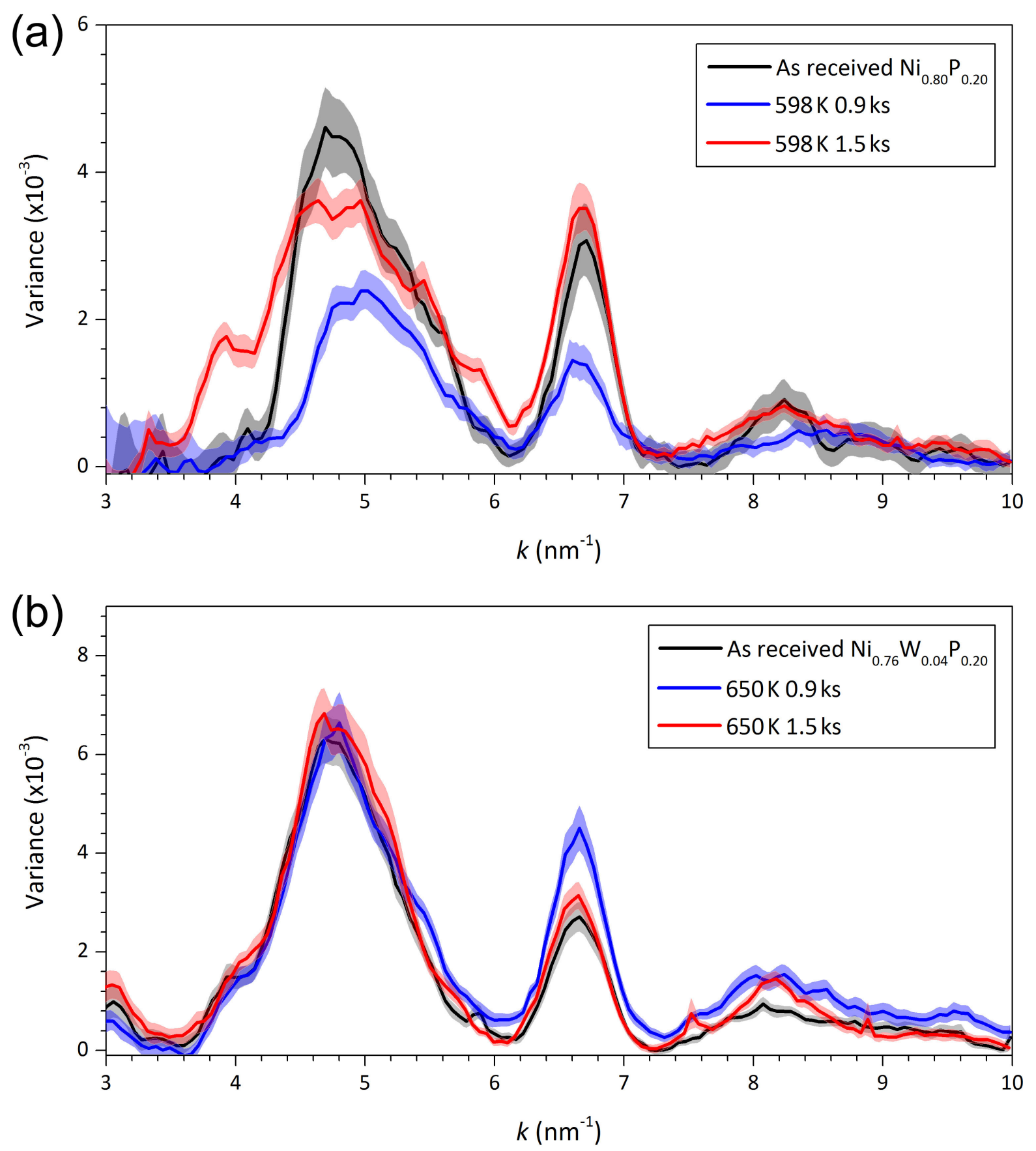

Figure 4: $\mathrm{FEM}$ of $\mathrm{Ni}_{0.80} \mathrm{P}_{0.20}$ and $\mathrm{Ni}_{0.76} \mathrm{~W}_{0.04} \mathrm{P}_{0.20}$ alloy. (a) As received, tempered at $598 \mathrm{~K} 0.9 \mathrm{ks}$ and $1.5 \mathrm{ks} \mathrm{Ni}_{0.80} \mathrm{P}_{0.20}$ alloy. (b) As received, tempered at $650 \mathrm{~K} 0.9 \mathrm{ks}$ and $1.5 \mathrm{ks} \mathrm{Ni} 0.76 \mathrm{~W}_{0.04} \mathrm{P}_{0.20}$ alloy. 

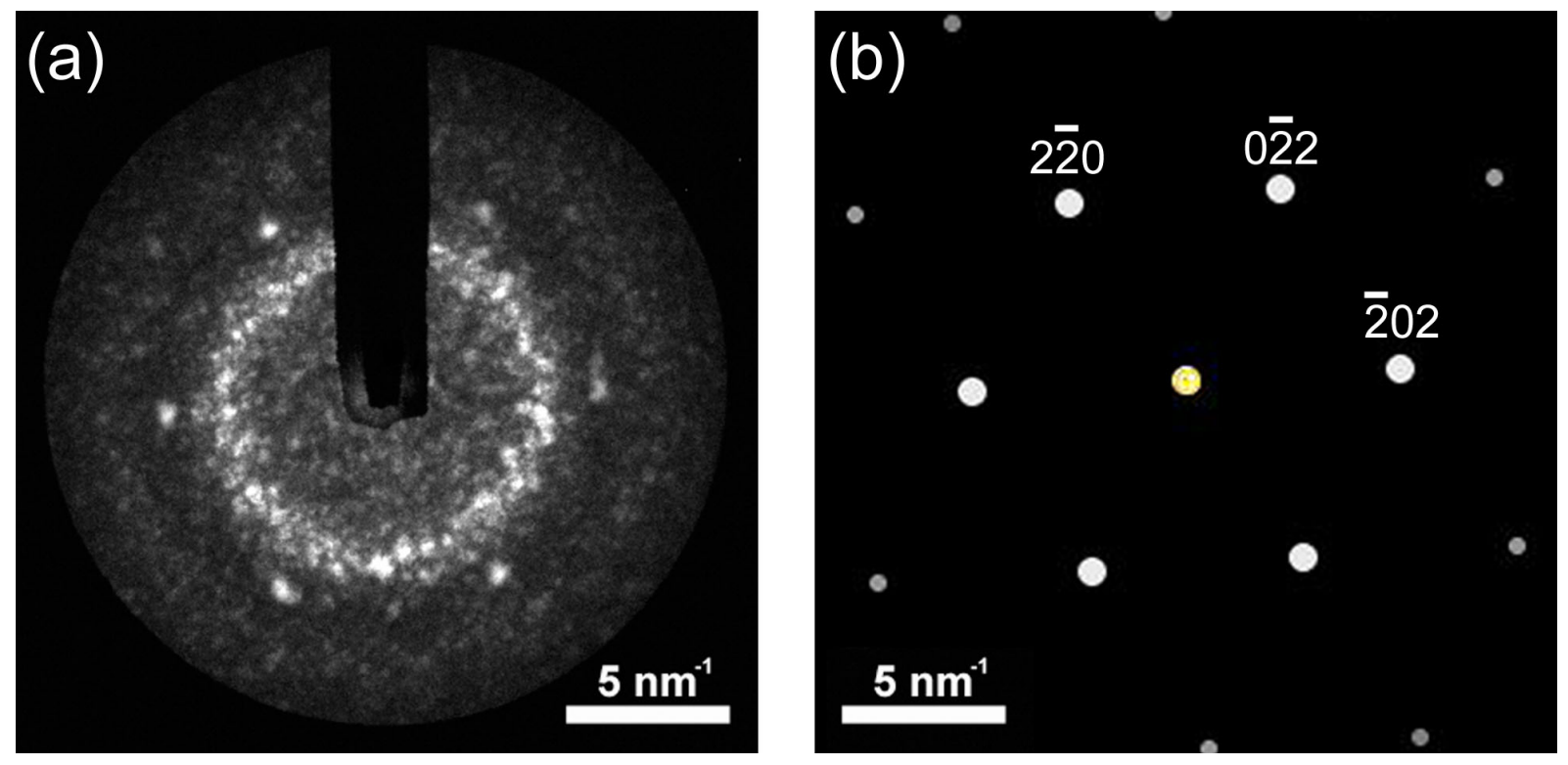

Figure 5: Diffraction patterns of (a) Typical nano-diffraction pattern shown 6-fold rotational symmetry in as received and tempered $\mathrm{Ni}_{0.80} \mathrm{P}_{0.20}$ and $\mathrm{Ni}_{0.76} \mathrm{~W}_{0.04} \mathrm{P}_{0.20}$ alloy, and (b) simulated diffraction pattern of $\mathrm{NiO}\langle 111\rangle$ zone axis.

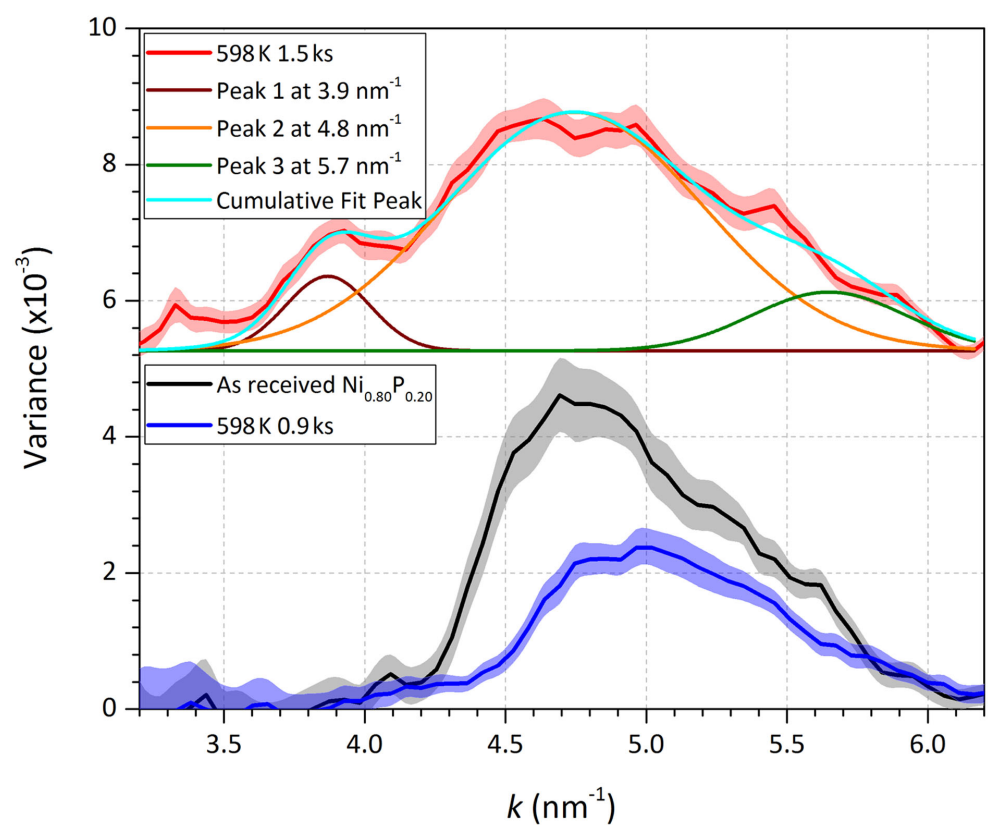

Figure 6: FEM of $\mathrm{Ni}_{0.80} \mathrm{P}_{0.20}$ in the as received condition and after tempering for $0.9 \mathrm{ks}$ and $1.5 \mathrm{ks}$ at $598 \mathrm{~K}$, respectively. The graphs show the experimentally determined variance $V[k]$ for the $k$ range between $3.2 \mathrm{~nm}^{-1}$ and $6.2 \mathrm{~nm}^{-1}$. The curve for $1.5 \mathrm{ks}$ was fitted by a superposition of three Gauß functions, denoted as "Peak 1," "Peak 2," and "Peak 3". 

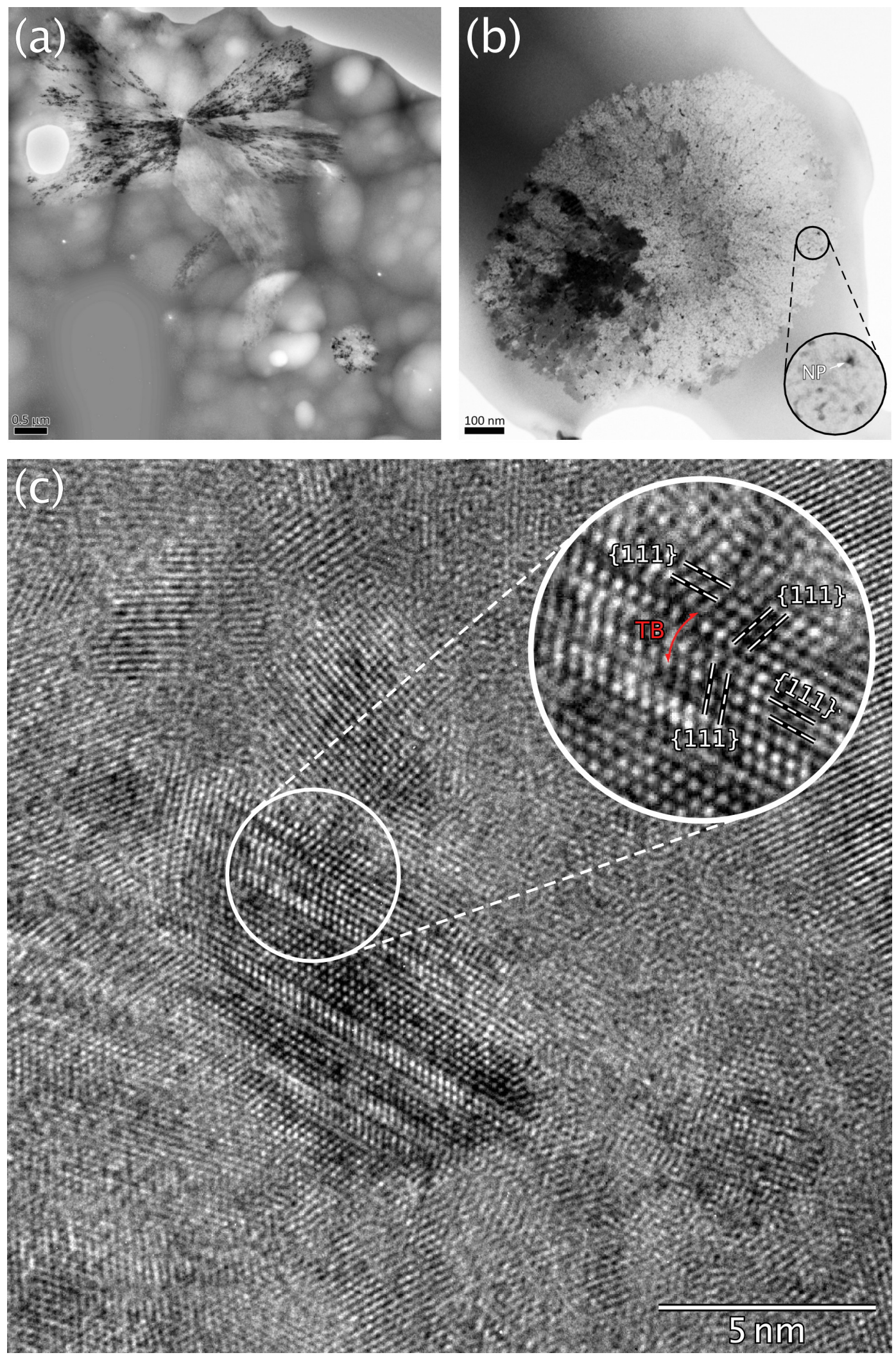

Figure 7: TEM bright-field images of partially crystallized $\mathrm{Ni}_{0.76} \mathrm{~W}_{0.04} \mathrm{P}_{0.20}$ alloy. (a) TEM bright-field image shown spherulite-like and elongated grains. (b) TEM bright-field image shown typical microstructure and nanoparticles (NP) in one grain. (c) HRTEM image of one nanoparticle, featuring stacking faults and twin boundaries (TB). 

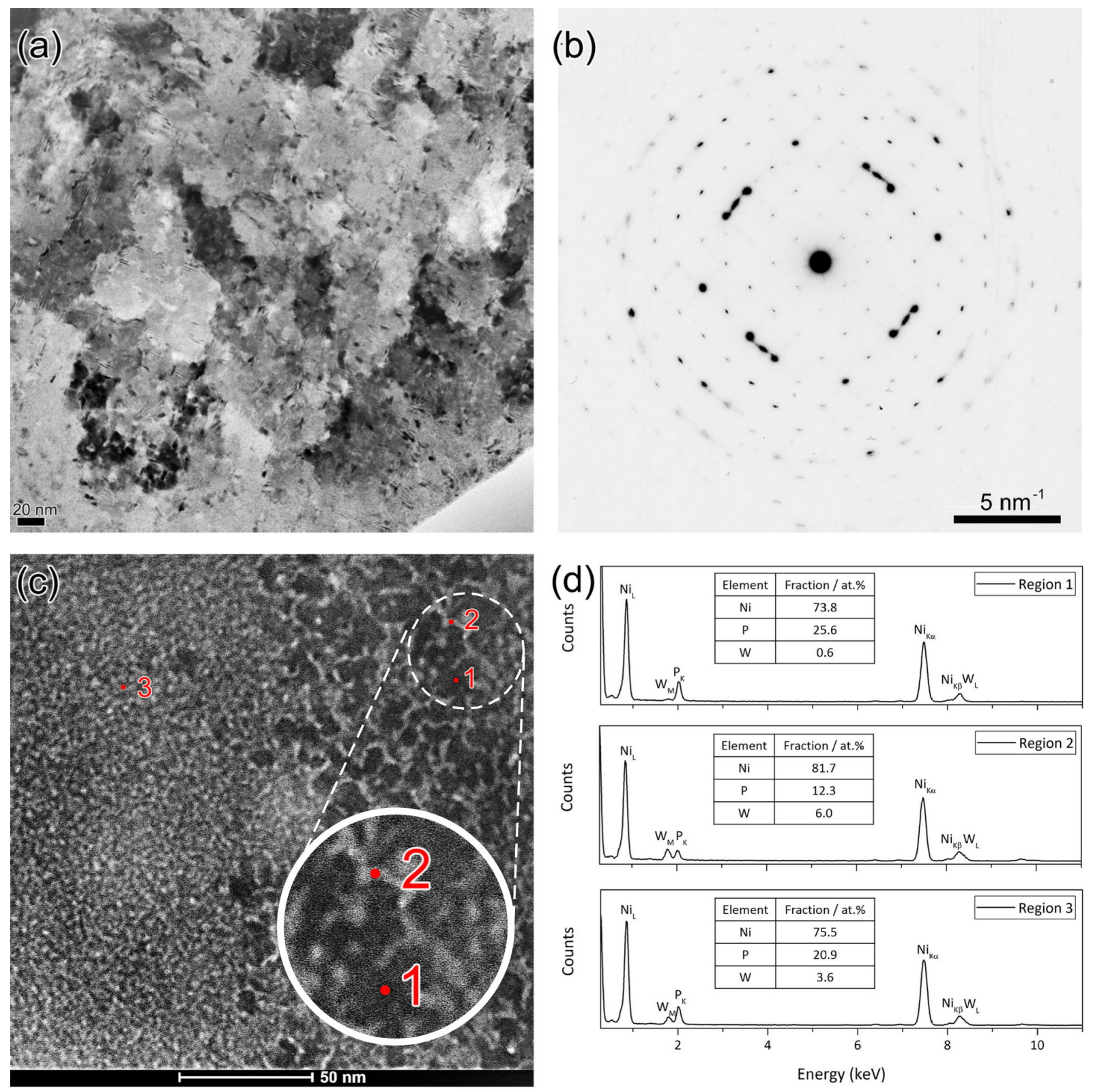

Figure 8: Partially crystallized nwp: TEM bright-field image, SADP (selected-area diffraction pattern), STEM image, and XEDS spectra of a tetragonal $\mathrm{Ni}_{3} \mathrm{P}$ grain (viewing direction: $\langle 001\rangle$ ). (a) TEM bright-field image, showing Ni nano-platelets that make $90^{\circ}$ with each other in the $\langle 001\rangle$ viewing direction. (b) SADP of this region. (c) STEM image showing "Z-contrast." (d) XEDS spectra from region 1 (dark), region 2 (bright), and region 3 (amorphous matrix). 
(a)

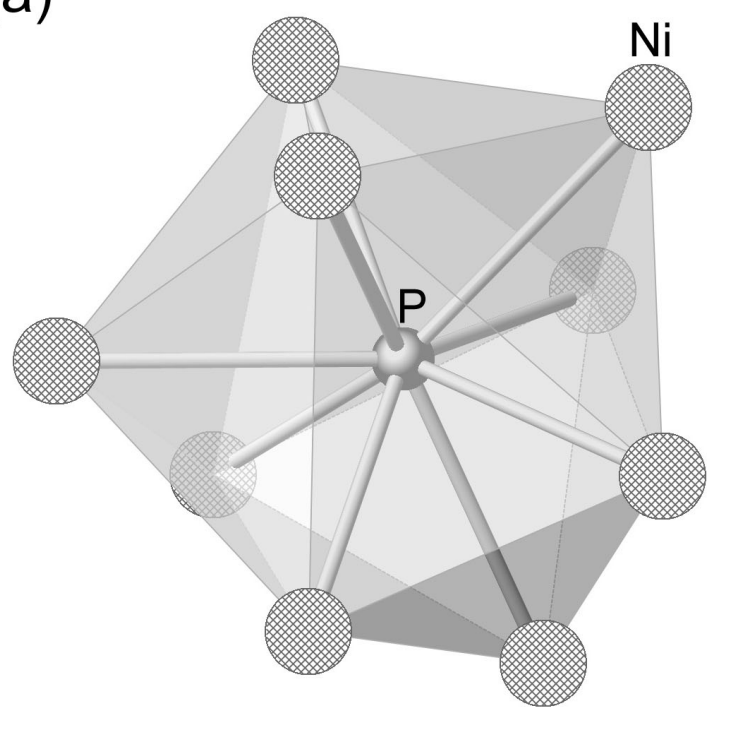

(b)

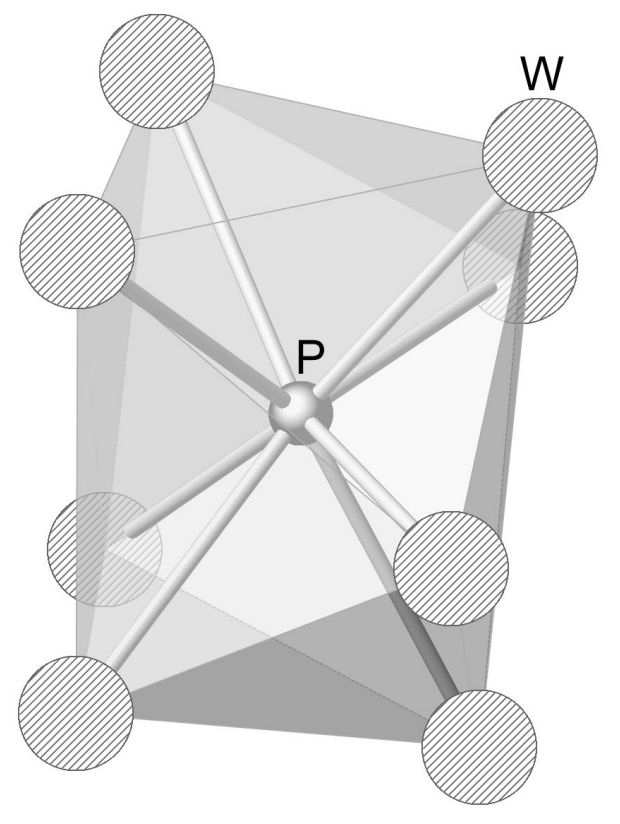

Figure 9: Structure unit in crystalline $\mathrm{Ni}_{3} \mathrm{P}$ and $\mathrm{W}_{3} \mathrm{P}$. (a) Nig 9 TTP. (b) $\mathrm{W}_{8} \mathrm{P}$ tetragonal dodecahedron. 
Atomistic Structure
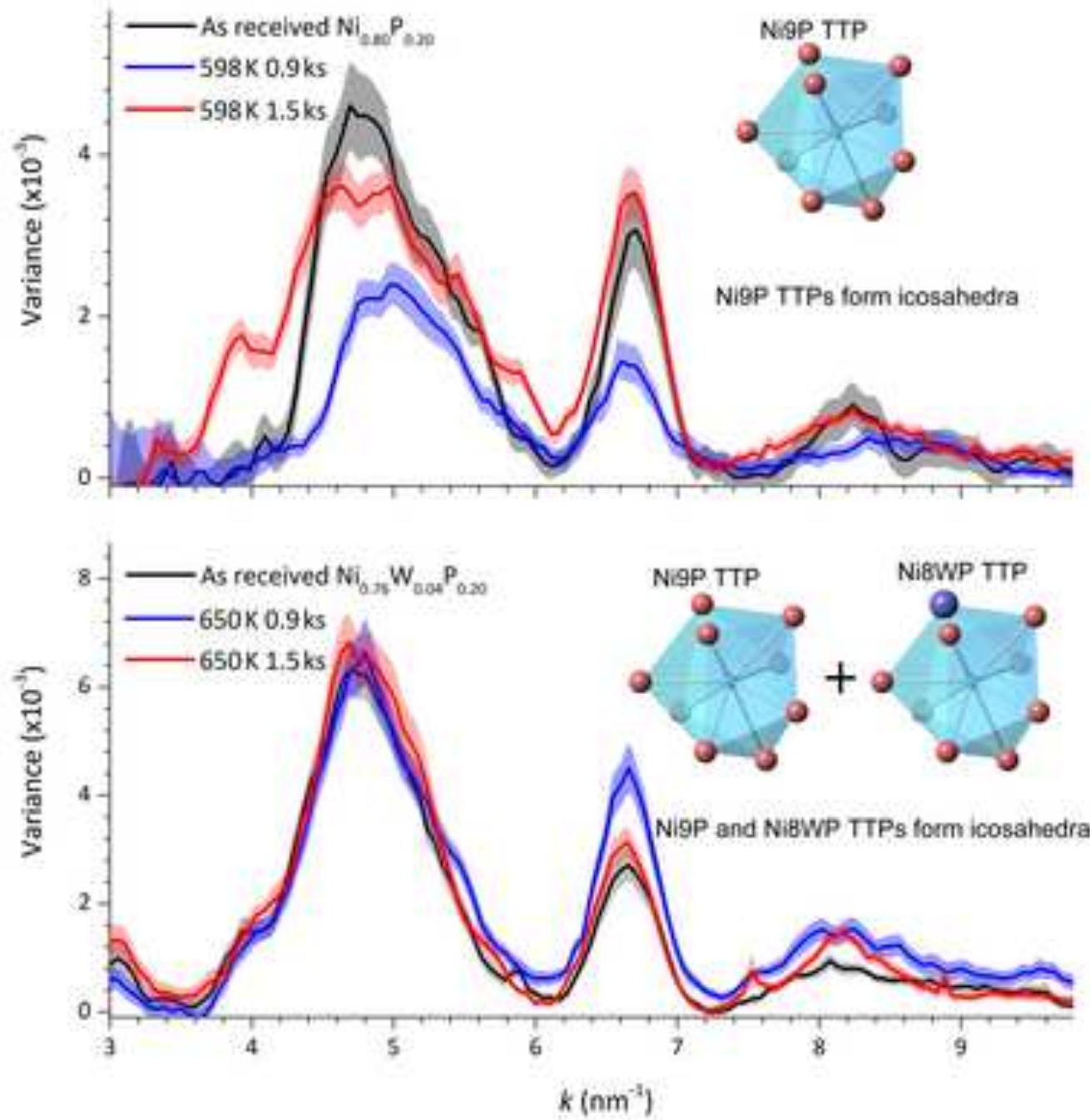

Microstructure
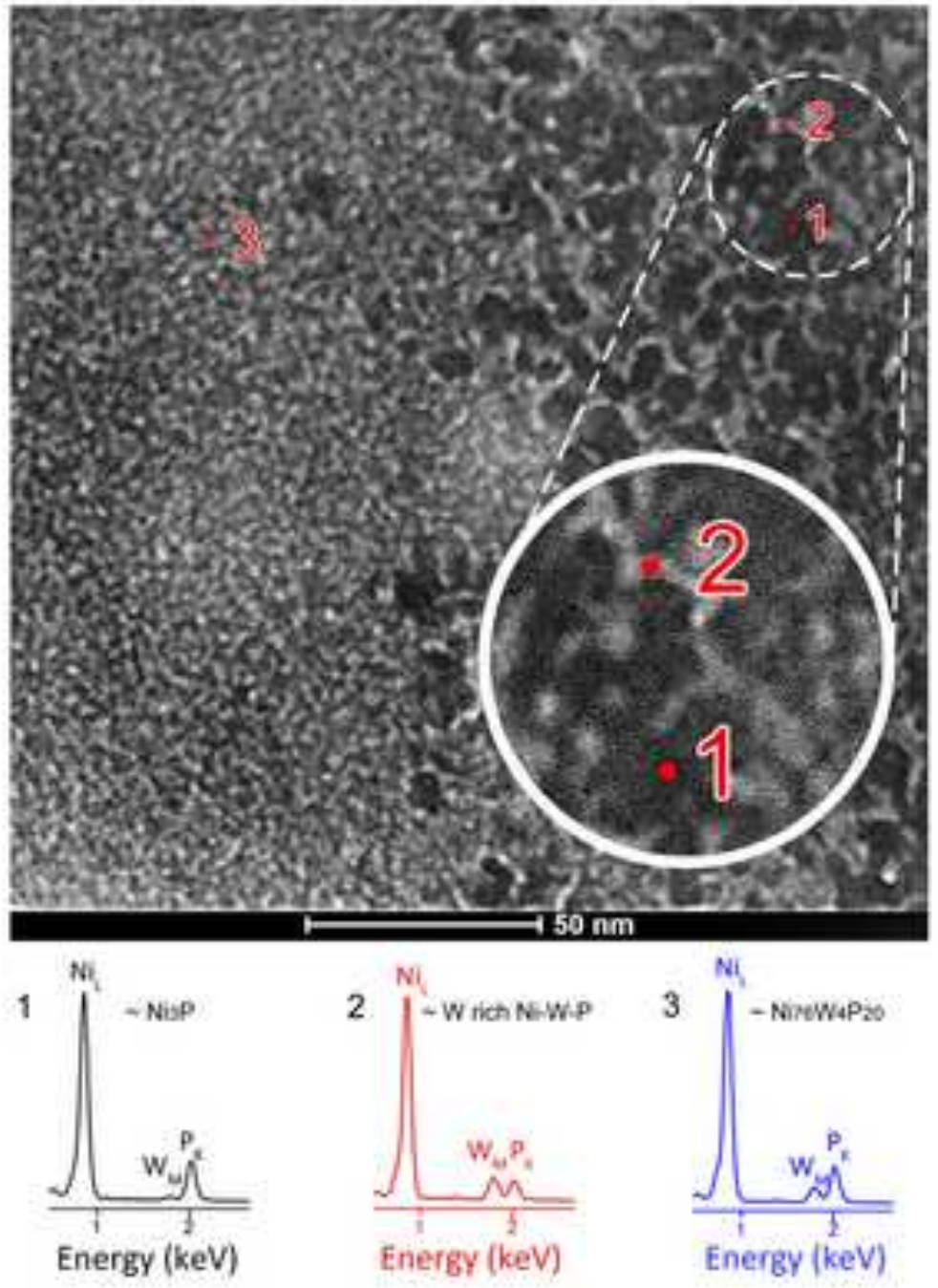